\title{
Elacestrant (RAD1901) exhibits anti-tumor activity in multiple ER+ breast cancer models resistant to CDK4/6 inhibitors
}

Hitisha K. Patel ${ }^{1}$, Nianjun Tao ${ }^{1}$, Kyung-Min Lee ${ }^{2}$, Mariela Huerta², Heike Arlt' ${ }^{1}$, Tara Mullarkey ${ }^{1}$, Steven Troy', Carlos L. Arteaga ${ }^{2}$ and Teeru Bihani ${ }^{i^{*}}$

\begin{abstract}
Background: Addition of CDK4/6 inhibitors (CDK4/6i) to endocrine therapy significantly increased progression-free survival, leading to their approval and incorporation into the metastatic breast cancer treatment paradigm. With these inhibitors being routinely used for patients with advanced estrogen receptor-positive (ER+) breast cancer, resistance to these agents and its impact on subsequent therapy needs to be understood. Considering the central role of ER in driving the growth of ER+ breast cancers, and thus endocrine agents being a mainstay in the treatment paradigm, the effects of prior CDK4/6i exposure on ER signaling and the relevance of ER-targeted therapy are important to investigate. The objective of this study was to evaluate the anti-tumor activity of elacestrant, a novel oral selective estrogen receptor degrader (SERD), in preclinical models of CDK4/6i resistance.
\end{abstract}

Methods: Elacestrant was evaluated as a single agent, and in combination with alpelisib or everolimus, in multiple in vitro models and patient-derived xenografts that represent acquired and "de novo" CDK4/6i resistance.

Results: Elacestrant demonstrated growth inhibition in cells resistant to all three approved CDK4/6i (palbociclib, abemaciclib, ribociclib) in both ESR1 wild-type and mutant backgrounds. Furthermore, we demonstrated that elacestrant, as a single agent and in combination, inhibited growth of patient-derived xenografts that have been derived from a patient previously treated with a CDK4/6i or exhibit de novo resistance to CDK4/6i. While the resistant lines demonstrate distinct alterations in cell cycle modulators, this did not affect elacestrant's anti-tumor activity. In fact, we observe that elacestrant downregulates several key cell cycle players and halts cell cycle progression in vitro and in vivo.

Conclusions: We demonstrate that breast cancer tumor cells continue to rely on ER signaling to drive tumor growth despite exposure to CDK4/6i inhibitors. Importantly, elacestrant can inhibit this ER-dependent growth despite previously reported mechanisms of CDK4/6i resistance observed such as Rb loss, CDK6 overexpression, upregulated cyclinE1 and E2F1, among others. These data provide a scientific rationale for the evaluation of elacestrant in a post-CDK4/6i patient population. Additionally, elacestrant may also serve as an endocrine backbone for rational combinations to combat resistance.

Keywords: Elacestrant, RAD1901, SERD, CDK4/6, Resistance, Palbociclib, Ribociclib, Abemaciclib, Breast cancer, Estrogen receptor

\footnotetext{
* Correspondence: tbihani@gmail.com

${ }^{1}$ Radius Health, Inc., 950 Winter St., Waltham, MA 02451, USA

Full list of author information is available at the end of the article
}

(c) The Author(s). 2019 Open Access This article is distributed under the terms of the Creative Commons Attribution 4.0 International License (http://creativecommons.org/licenses/by/4.0/), which permits unrestricted use, distribution, and reproduction in any medium, provided you give appropriate credit to the original author(s) and the source, provide a link to the Creative Commons license, and indicate if changes were made. The Creative Commons Public Domain Dedication waiver (http://creativecommons.org/publicdomain/zero/1.0/) applies to the data made available in this article, unless otherwise stated. 


\section{Introduction}

Breast cancer remains one of the most commonly diagnosed cancers in women and has affected over 200,000 women in the USA in 2018 alone [1, 2]. A majority ( $70 \%$ ) of breast cancers express the estrogen receptor (ER) and are driven by active ER signaling and corresponding transcription of genes that are important for tumor growth [2-5]. Current therapies for ER+ breast cancer rely heavily on their ability to block ER signaling either by inhibiting the synthesis of estradiol (aromatase inhibitors (AIs)) or by inhibiting ER signaling through competitive binding to the receptor itself [selective estrogen receptor modulators (SERMs) and selective estrogen receptor degraders (SERDs)] [6-9]. In the context of metastatic disease, dependence on active ER signaling is often maintained in metastatic lesions, leading to the continued use of endocrine agents such as AIs, tamoxifen (SERM), or fulvestrant (SERD) in this setting $[10,11]$.

While endocrine monotherapy has been a mainstay in treating metastatic ER+ breast cancer for decades, multiple pivotal clinical trials in recent years have demonstrated that the addition of cyclin-dependent kinase $4 / 6$ inhibitors (CDK4/6i) to an endocrine agent, such as an aromatase inhibitor or a SERD such as fulvestrant, significantly increases progression-free survival (PFS) when compared to the endocrine agent alone [5, 12-17]. These trials led to the approval of the first-in-class CDK4/6i, palbociclib, followed closely by the approval of two additional CDK4/6 inhibitors, ribociclib and abemaciclib, both in the first-line and second-line settings for ER+ advanced breast cancer [18-20].

Recent overall survival (OS) data demonstrate that patients derive benefit from the combination of CDK4/6i with endocrine therapy. In patients with prior endocrine sensitivity in the PALOMA-3 trial, treatment with palbociclib and fulvestrant led to longer OS (10 months) than treatment with placebo and fulvestrant [21]. The MONALEESA-3 [22] and MONALEESA-7 trials demonstrated that both pre- and postmenopausal patients derived OS benefit from the addition of ribociclib to endocrine therapy, with a median OS not reached in either trial in the combo arm vs 40.0 months and 40.7 months, respectively, in the single-agent arms [23]. The MONARCH-2 trial demonstrated that treatment with abemaciclib plus fulvestrant resulted in a statistically significant median OS improvement of 9.4 months for patients who progressed after prior endocrine therapy regardless of menopausal status [24].

While the addition of a CDK4/6i to endocrine therapy approximately doubles PFS and improves OS, a portion of these patients will eventually relapse and will require additional treatment. It is important, therefore, to understand the molecular makeup of a tumor that has progressed on CDK4/6i treatment, in order to help inform subsequent treatment options. Several CDK4/6i resistance mechanisms have been described preclinically, including multiple alterations of the cell cycle pathway such as cyclin E1/E2 amplification, E2F1 overexpression, retinoblastoma protein $(\mathrm{Rb})$ loss, and CDK6 overexpression driven by the loss of the tumor suppressor FAT1 among others $[2,25-28]$. In the clinic, mutations in the $\mathrm{Rb}$ gene have been detected in patients after palbociclib treatment [29]; however, some studies suggest that these mutations are of low prevalence in breast cancer and are not likely to be a major mechanism of resistance [30-33]. While these mechanisms of resistance and their relevance in the clinic are currently being examined, a few key questions ariseDo these resistance mechanisms alter ER-driven tumor growth, and does an ER-targeted agent continue to be effective in patients with prior CDK4/6i therapy? Does the presence of constitutively active ESR1 mutations have an impact on the extent of ER-dependent tumor growth?

ER signaling is known to regulate several proteins that are important for cell cycle progression [5, 34, 35]. It has been previously demonstrated that ER regulates the expression of cyclin D1, a protein that complexes with CDK4/6, which in turn, phosphorylates and inactivates $\mathrm{Rb}$, thus resulting in cell cycle progression [2, 34, 36]. Furthermore, ER is known to activate the expression of E2F1 which plays a major role in cell cycle progression through transcription of genes such as cyclin E1 [37, 38]. The impact that ER signaling has on genes heavily involved in cell cycle regulation may explain why the combination of antiestrogens and CDK4/6i is so effective. It also suggests that endocrine therapies will remain a mainstay in the treatment of breast cancer.

Given the impact of ER on cell cycle progression, it is important to evaluate antiestrogen therapy in a postCDK4/6i setting. Fulvestrant, the only approved SERD, is effective in patients; however, its low oral bioavailability and intramuscular route of administration pose some limitations $[39,40]$. This has spurred the discovery of new orally administered SERDs that can overcome these limitations. Herein, we assess the activity of elacestrant (RAD1901), an orally bioavailable SERD [41, 42], in CDK4/6i-resistant preclinical models. Elacestrant has demonstrated partial responses in patients with prior CDK4/6i therapy in phase I clinical trials (NCT02338349) [43]. Currently, elacestrant is being investigated in a phase III clinical trial (NCT03778931) in patients that have received prior CDK4/6i therapy [44]. Additionally, this will be among the first clinical trials to prospectively examine the effects of ESR1 mutations on response to hormonal therapies, which is important with respect to recent analyses demonstrating the selection of specific ESR1 mutations upon fulvestrant treatment [30]. We provide evidence demonstrating ER-driven tumor growth in a post-CDK4/6i tumor setting and preclinical rationale for the examination of elacestrant in patients that have progressed on a CDK4/6i. 


\section{Materials and methods}

\section{Reagents and cell lines}

Elacestrant (RAD1901) ((6R)-6-(2-(N-(4-(2-(ethylamino)ethyl)benzyl)-N-ethylamino)-4-methoxyphenyl)5,6, 7,8-tetrahydronaphthalen-2-ol dihydrochloride) was manufactured by Patheon. Elacestrant lots used in this study were periodically checked to ensure purity, stability, and chirality. HCC1428 cells were purchased from ATCC, and HCC1428-LTED (long-term estrogen deprived) were developed by maintaining the cells in RPMI phenol red-free medium supplemented with 10\% charcoal-stripped FBS (HyClone, GE Healthcare Life Sciences) and 1\% pen-strep (Thermo Fisher Scientific) at 5\% $\mathrm{CO}_{2}$. MCF7 cells harboring wild-type ER were genetically modified using CRISPR-Cas9 to express either the ESR1:Y537S or the ESR1:D538G mutated proteins. Briefly, single-guide RNAs were utilized to create the $\mathrm{KI} / \mathrm{KI}$ cell line containing ESR1: $Y 537 S$ and the $\mathrm{KI} / \mathrm{KO}$ cell line containing ESR1: $D 538 G$, and single-cell clones were isolated and grown to establish these cells. The MCF7-Y537S/D538G cell lines were maintained in RPMI phenol red-free medium supplemented with $10 \%$ charcoal-stripped FBS (HyClone, GE Healthcare Life Sciences) and 1\% pen-strep (Thermo Fisher Scientific) at $5 \% \mathrm{CO}_{2}$.

\section{Development of CDK4/6 inhibitor resistance In vitro}

HCC1428-LTED-Palbo $^{\mathrm{R}}$, HCC1428-LTED-Ribo ${ }^{\mathrm{R}}$, and HCC1428-LTED-Abema $^{R}$ cells were developed by exposing the HCC1428-LTED cells to increasing concentrations of the respective CDK4/6i to a final concentration of $500 \mathrm{nM}$ for palbociclib, $1 \mu \mathrm{M}$ for ribociclib, and $250 \mathrm{nM}$ for abemaciclib. MCF7-LTED-Y537SCDK4/6i ${ }^{\mathrm{R}}$ and MCF7-LTED-D538G-CDK4/6i ${ }^{\mathrm{R}}$ cell lines were developed by exposing MCF7-LTED-Y537S and MCF-LTED-D538G cells, respectively, to increasing concentrations of the respective CDK4/6i to a final concentration of $500 \mathrm{nM}$ for palbociclib, $1 \mu \mathrm{M}$ for ribociclib, and 250 $\mathrm{nM}$ for abemaciclib. Doses for generating resistant cell lines were chosen based upon the previously reported literature $[25,45,46]$. The ESR1 wild-type resistant cells exhibited a resistant phenotype after 10-12 months of drug exposure. The ESR1-mutant resistant cell lines exhibited a resistant phenotype after 6-10 months of drug exposure. After resistance was established, cells were maintained at $500 \mathrm{nM}$ of palbociclib for Palbo $^{\mathrm{R}}$ cells, $1 \mu \mathrm{M}$ ribociclib for $\mathrm{Ribo}^{\mathrm{R}}$ cells, and $250 \mathrm{nM}$ of abemaciclib for Abema ${ }^{\mathrm{R}}$ cells. MCF7 cells harboring wild-type ER were cultured in LTED conditions to serve as the control for the MCF7 cells harboring ESR1 mutations. The MCF7-WT-LTED cells lost ER expression (data not shown) and were not studied further. HCC-1428-LTED cells were used to understand CDK4/6 inhibitor resistance in a wild-type ER setting.

\section{In vivo}

ST941-HI (hormone-independent) patient-derived xenograft (PDX) fragments were implanted into ovariectomized athymic nude mice. Tumors were measured twice/week, with Vernier calipers; volumes were calculated using the following formula: $\left(L \times W^{2}\right) \times 0.5$, where $L$ is the length and $W$ is the width in millimeters of the tumor. Once average tumor size reached $200 \mathrm{~mm}^{3}$, animals were either treated with vehicle, fulvestrant (3 mg/dose, weekly) + palbociclib (25 mg/ kg, daily), or elacestrant $(30 \mathrm{mg} / \mathrm{kg}$, daily). Tumors growing in the presence of fulvestrant $(3 \mathrm{mg} /$ dose/week $)+$ palbociclib ( $25 \mathrm{mg} / \mathrm{kg}$ daily) were allowed to grow at least $1500 \mathrm{~mm}^{3}$ and then harvested and re-implanted into a new cohort of mice considered as passage $\mathrm{P} 1$. This process was repeated to establish the subsequent passages (P2 and P3). The dose of palbociclib was reduced to $10 \mathrm{mg} / \mathrm{kg}$ in P3 to assess palbociclib activity at a clinically relevant dose (Additional file 1: Figure S3).

\section{In vitro cell proliferation assays}

Briefly, HCC1428-LTED and HCC1428-LTED-CDK4/ $6 \mathrm{i}^{\mathrm{R}}$ cell lines were seeded in 96-well plates at a density of 5000 cells/well. MCF7-LTED-Y537S, MCF7-LTED-Y537SCDK4/6i ${ }^{\mathrm{R}}$, MCF7-LTED-D538G, and MCF-7-LTEDD538G-CDK4/6 $\mathrm{i}^{\mathrm{R}}$ were seeded in 96-well plates at a density of 2000 cells/well. Twenty-four hours post-plating, cells were treated with the respective CDK4/6i or elacestrant. Cells were incubated in the indicated treatments for 7 days, and cell growth was measured using the CellTiter-Glo assay (Promega) as per the manufacturer's instructions. Data was normalized to the control values as $100 \%$, and data is graphed as the percentage of growth relative to control at day 7.

\section{Colony formation assay}

Cells were plated at a density of 1000-10,000 cells/well in 6-well plates. Twenty-four hours post-seeding, cells were treated with the indicated compounds [palbociclib (500 nM), ribociclib $(500 \mathrm{nM})$, abemaciclib (250 nM), elacestrant (300 nM)]. Colonies were allowed to grow for $2-5$ weeks depending on the growth rate of each cell line. The treatments were performed in triplicate, and media and drug were replaced weekly. At the end of the treatment, cells were fixed in paraformaldehyde and stained with $0.05 \%$ crystal violet for visualization. A representative well is pictured (Figs. 1 and 3).

\section{Western blotting}

Cells were harvested and lysed in CelLytic ${ }^{\mathrm{MT}}$ lysis buffer (Sigma-Aldrich) after either 24 or $48 \mathrm{~h}$ of treatment, and total protein was separated by SDS-PAGE and transferred to the membranes and immunostained using antibodies specific to the indicated proteins. For in vivo 


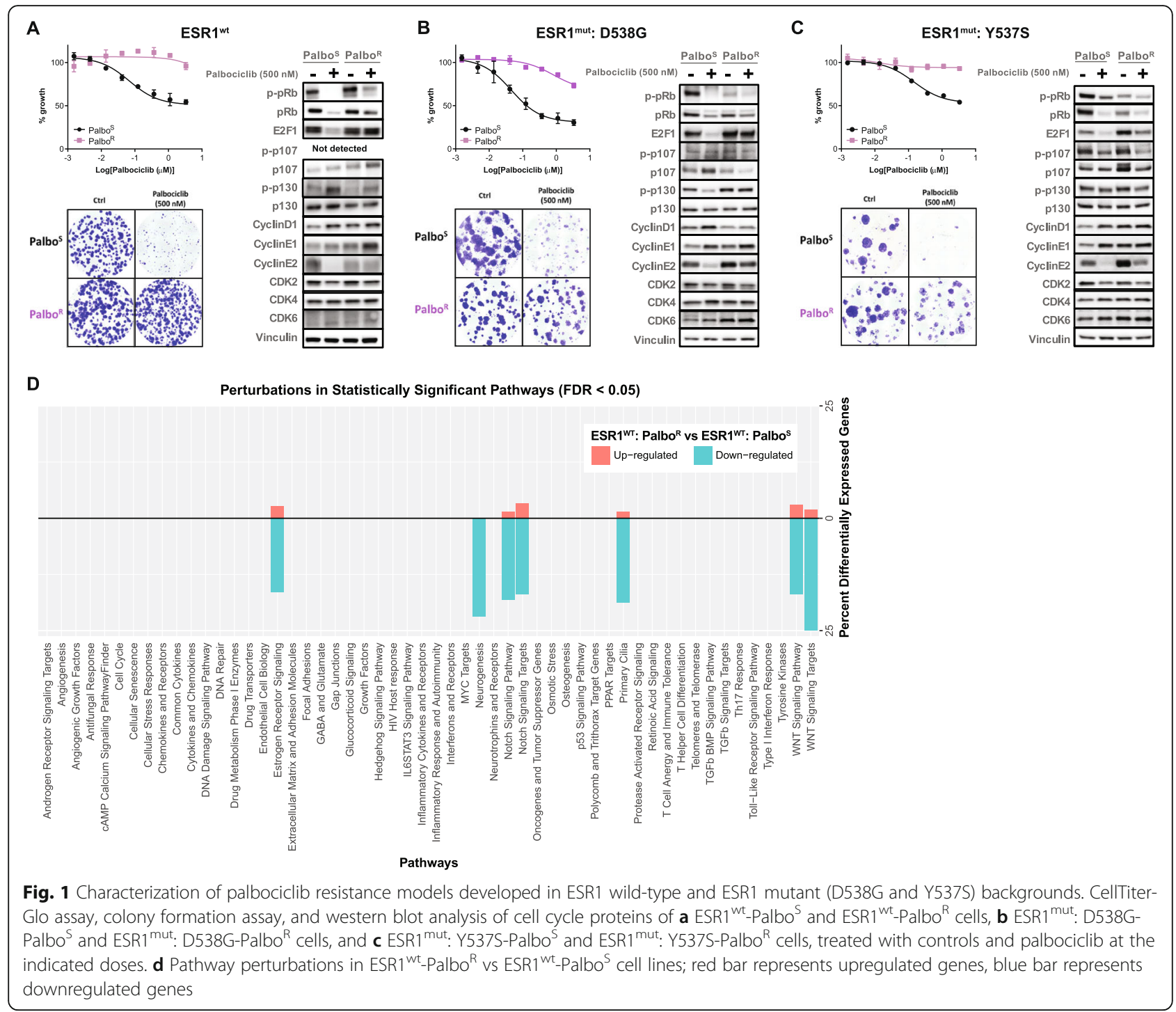

pharmacodynamic studies, end of study flash-frozen tumors ( $4 \mathrm{~h}$ post-last dose) were fractured using a cryoPREP instrument (Covaris), and pulverized tissue was lysed in CelLytic ${ }^{\mathrm{MT}}$ lysis buffer (Sigma-Aldrich). Total protein was analyzed by Western blot analysis as described above. Protein expression was analyzed using standard practice and antibodies as follows: ER $\alpha, \mathrm{PR}$, E2F1, CCNE1, CCNE2, CCND1, total Rb, phospho-Rb S807/811, CDK2, CDK4, CDK6, Actin (Cell Signaling Technologies, Catalog \#13258, \#3153, \#3742, \#20808, \#4132, \#2978, \#9309, \#8516, \#2546, \#12790, \#13331, \#4970, respectively), phospho-p107, p107, phosphop130, p130 (Abcam: ab111348, ab76255, ab168458, ab6545, respectively), GREB1 (Millipore, MAB562), and Vinculin (Sigma-Aldrich, \#v9131). Protein expression was quantified using the AzureSpot software and normalized to the expression of the vinculin protein.

\section{Quantitative reverse transcriptase PCR analyses}

For cell lines, quantitative reverse transcriptase PCR analysis was performed using the Cells to $C_{T}$ kit (Life Technologies), and the lysates were processed according to the manufacturer's instructions. qRT-PCR was performed using the one-step master mix and TaqMan ${ }^{\text {Tm }}$ probes (Applied Biosystems). For in vivo pharmacodynamic studies, end of study flash-frozen tumors were pulverized using the cryoPREP instrument (Covaris). From the pulverized tissue, total RNA was extracted using the RNeasy Mini Kit (Qiagen); qRT-PCR was performed using the TaqMan Fast Virus One-Step Master Mix and TaqMan ${ }^{\mathrm{Tm}}$ probes (Applied Biosystems). The $\mathrm{C}_{\mathrm{T}}$ values were analyzed to assess the relative changes in the expression of the TFF1 (trefoil factor 1/breast cancer estrogen-inducible protein; Hs00907239_m1), GREB1 (gene regulated by estrogen in breast cancer 1; 
Hs00536409_m1), and PGR (progesterone receptor; Hs01556702_m1) genes, with GAPDH (4310884E) as an internal control, using the $2^{\wedge}-\Delta \Delta \mathrm{C}_{\mathrm{T}}$ method [47].

\section{RNA sequencing}

RNA was extracted from HCC1428-LTED and HCC1428-LTED-Palbo $^{\mathrm{R}}$ cell lines using the RNeasy Mini Kit (Qiagen), according to the manufacturer's instructions. The total RNA library was prepared by quantifying purified RNA by Qubit method and assessing RNA quality and intactness by the Agilent Bioanalyzer. All RNA samples were normalized to $100 \mathrm{ng}$ for the library preparation. The resulting libraries were normalized to size-adjusted molarity of $2 \mathrm{nM}$. The samples were processed according to the TS RNA Access protocol and sequenced according to the standard sequencing protocol using $2 \times 100 \mathrm{bp}$ PE sequencing on an Illumina HiSeq sequencing platform. Raw reads quality control and clipping and trimming of sequences were performed by fastq-mcf. Cleaned reads were mapped to the human genome by STAR software v2.4. Pairwise differential expression testing was performed using Expression analysis (EA) Genomics' Ensemble two group comparisons suite. In brief, EA's Ensemble method summarizes the differential expression $p$ values and classification probabilities from five popular tools $-t$ test, limma, DESeq2, edgeR, and EBSeq-to produce a new $p$ value for differential expression which has demonstrated proper type I error control and superior sensitivity. Aspects of each component test were utilized as input to a logistic regression model trained on data from The Cancer Genome Atlas (TCGA) which produces an estimate of the probability that a gene is differentially expressed between two conditions. This value is further transformed to a proper $p$ value by comparison against its empirical cumulative distribution under the null established via bootstrap resampling of TCGA data from various cancer types.

\section{Patient-derived xenografts}

All study protocols were reviewed by Radius, approved by Institutional Animal Care and Use Committees (IACUC), and conducted in accordance with the US and International regulations for the protection of laboratory animals. Female athymic nude mice (NU(NCr)-Foxn1nu or BALB/cAnNCrl-Foxn1nu) were obtained from Envigo RMS, Inc., Jackson Laboratories, Harlan Laboratories, or Charles River Laboratories and acclimated for 3 to 7 days prior to implantation. All mice were housed in pathogenfree housing in individually ventilated cages with sterilized and dust-free bedding cobs, access to sterilized food and water ad libitum, under a light-dark cycle (12-14 h circadian cycle of artificial light), and controlled room temperature and humidity. The WHIM43-HI PDX was derived and studied at Horizon (Saint Louis, MO). The
ST941-HI and ST3932 PDX models were derived and studied at South Texas Accelerated Research Therapeutics (San Antonio, TX). The CTG-2308 and CTG-2432-HI PDX models were derived and studied at Champions Oncology (Rockville, MD). The PDX-R1 model was derived and studied at UT Southwestern Simmons Cancer Center. All animals were subcutaneously implanted with PDX models. When tumors grew to $150-200 \mathrm{~mm}^{3}$, mice were randomized based on tumor volume and administered the indicated treatments. Tumors were measured twice/week with Vernier calipers; volumes were calculated using the following formula: $\left(L \times W^{2}\right) \times 0.5$, where $L$ is the length and $W$ is the width in millimeters of the tumor. Elacestrant, palbociclib, alpelisib (byl-719), and everolimus were administered orally and daily for the duration of the study. Preformulated, clinical-grade fulvestrant (Faslodex, manufactured by AstraZeneca) was obtained through third-party vendors and administered by subcutaneous injection once weekly. At the end of the study, tumors were harvested $4 \mathrm{~h}$ post-last dose unless otherwise indicated.

\section{In vivo pharmacokinetic analyses}

The protocol for the animal experiment was approved by the Institutional Animal Care and Use Committee (IACUC) and conducted in accordance with the US and International regulations for the protection of laboratory animals. Athymic nude (FoxN1/NCR) mice of 6-8 weeks of age were provided by the Charles River Laboratories (Wilmington, MA). Mice were housed four per cage and fed 5060 (irradiated) chow from Lab Diet ad libitum. Prior to the start of the study, mice were randomized into groups based on the average body weight. Mice were given a single dose of palbociclib (formulated in $0.9 \%$ sodium chloride at $10 \mathrm{mg} / \mathrm{ml}$ ) at either $2.5,7.5,25$, or $75 \mathrm{mg} / \mathrm{kg}$. Each animal was used for a total of four time points for blood collection. Time points for blood collection were $1,2,4,6,8,12,24,36,48$, and $72 \mathrm{~h}$. The blood was collected from the mandibular vein, and no more than $100 \mu \mathrm{l}$ of blood was taken at a single time. The final blood collection was a terminal cardiac puncture. All blood was collected in K2-EDTA tubes. The whole blood was spun down for $10 \mathrm{~min}$ at $12,000 \mathrm{rpm}$ to separate the plasma. The plasma was stored at $-20^{\circ} \mathrm{C}$ for LC-MS analyses.

\section{Statistical analysis and data analysis}

Statistical and graphical presentations were performed using GraphPad Prism 7. For cell proliferation assays, the $\mathrm{IC}_{50}$ was calculated by fitting a dose-response curve using a nonlinear regression model with a $\log$ (inhibitor) vs response curve fit. Relative $\mathrm{IC}_{50}$, determined as the concentration where $50 \%$ of the maximal response is observed, was calculated by the GraphPadPrism 7.0 curve fitting software. For all xenograft studies, body weights 
and tumor volumes were evaluated twice weekly. Tumors were measured twice/week with Vernier calipers; volumes were calculated using the following formula: $\left(L \times W^{2}\right) \times 0.5$, where $L$ is the length and $W$ is the width in millimeters of the tumor. Tumor volumes were generally represented as mean \pm SEM. Statistical evaluations of the differences between the groups were assessed using one-way ANOVA with Dunnett's posttest. Percent tumor growth inhibition (\%TGI) was calculated as [ 1 - (average relative tumor volume treatment group $/$ average relative tumor volume vehicle group $)] \times 100$.

\section{Results}

\section{CDK4/6 inhibitors (CDK4/6i) exhibit differential activity in} relevant breast cancer cells

The efficacy of the three CDK4/6i, palbociclib, ribociclib, and abemaciclib, was tested in breast cancer cell lines that represent an AI-resistant/long-term estrogen deprived (LTED) setting and harbor either wild-type (HCC1428-LTED, abbreviated as ESR1 ${ }^{\mathrm{wt}}$ ) or mutant (MCF7-LTED-D538G and MCF7-LTED-Y537S, abbreviated as ESR1 ${ }^{\text {mut }}$ : D538G and ESR1 ${ }^{\text {mut }}$ : Y537S, respectively) ER. These cells are herein referred to as "CDK4/ 6i-sensitive" cell lines. All three CDK4/6i significantly inhibited the proliferation of these cells with varied potency and extent of inhibition (Fig. 1, Additional file 1: Figure S1). In the short-term proliferation assay, abemaciclib exhibited the greatest potency and extent of growth inhibition among the three CDK4/6i, whereas the antiproliferative effects of palbociclib and ribociclib varied depending on the cell line tested (Fig. 1, Additional file 1: Figure S1). Long-term ribociclib treatment of the CDK4/ 6i-sensitive cell lines only resulted in a partial growth inhibition in the colony formation assays, whereas treatment of cells with abemaciclib or palbociclib resulted in a more complete growth inhibition (Fig. 1, Additional file 1: Figure S1).

\section{Generation of CDK4/6i-resistant cells lines after long-term exposure}

To model clinical resistance to CDK4/6i therapy preclinically, we exposed estrogen-independent, CDK4/6i-sensitive breast cancer cell lines described above to increasing concentrations of each of the three CDK4/6i over a period of 6-12 months. The cell lines that were not exposed to CDK4/6i Palbo $^{\mathrm{S}}$ (palbociclib-sensitive), Ribo ${ }^{\mathrm{S}}$ (ribociclibsensitive), Abema ${ }^{\mathrm{S}}$ (abemaciclib-sensitive)] and the cells that were exposed to CDK4/6i [Palbo $^{\mathrm{R}}$ (palbociclib-resistant), Ribo ${ }^{\mathrm{R}}$ (ribociclib-resistant), Abema ${ }^{\mathrm{R}}$ (abemaciclib-resistant)] were assessed in short- and long-term proliferation assays. The resistant cell lines exhibited decreased sensitivity to the respective CDK4/6i in both assays (Fig. 1, Additional file 1: Figure S1). A shift in the $\mathrm{IC}_{50}$, as well as a reduction in the extent of growth inhibition, was observed in the resistant lines upon treatment with the same CDK4/6 inhibitor. Growth inhibition in response to the drug was completely lost in some of the resistant cell lines, and in one case, the growth of ESR1 ${ }^{\text {mut: }}$ Y537S-Abema ${ }^{R}$ cells was stimulated by the presence of abemaciclib in the colony formation assay. Other cells selected for resistance, such as the ESR1 ${ }^{\text {mut }}$ : D538GAbema ${ }^{R}$ cells, maintained sensitivity to abemaciclib treatment, albeit to a lesser extent when compared to their respective parental counterparts. Nevertheless, the observed shift in $\mathrm{IC}_{50}$, reduced extent of maximal growth inhibition, and the ability of cells to form colonies in the presence of the respective CDK4/6i marked a "resistant" phenotype (Fig. 1, Additional file 1: Figure S1).

\section{CDK4/6i-resistant models exhibit distinct changes in key cell cycle proteins}

To identify the molecular mechanisms for the observed resistance, both the sensitive and the resistant cell lines were treated short term $(24 \mathrm{~h})$ with the corresponding CDK4/6i and compared to their respective controls (no treatment for the duration of assay). The observed molecular changes are summarized in Additional file 1: Table S1.

The most frequently observed finding was upregulation in the expression of E2F1 and its downstream target cyclin E1 (CCNE1) (Additional file 1: Table S1). Considering the role of E2F1 as a positive regulator of transcription and cyclin E1 as an important player in cell cycle progression, these observations fit the profile of cycling cells and are in line with the previous observations $[25,26]$. Consistent with a study by Yang et al., marked decreases seen in E2F1 expression upon CDK4/ 6i treatment in the sensitive setting [25] were no longer observed in the resistant lines (Fig. 1, Additional file 1: Figure S1). We also observed phosphorylation of Rb despite CDK4/6i treatment of the resistant lines. These data suggest continued G1-S transition and cell cycle progression, demonstrating a loss of typical response to a CDK4/6i and an acquired "resistant" phenotype.

Modulation of $\mathrm{Rb} / \mathrm{Rb}$ family members, cyclinsD1/E2, and cyclin-dependent kinases varied in the resistant cell lines, implying that these cells adapt differently to CDK4/6i exposure (Additional file 1: Table S1), although ultimately converging to an upregulated E2F1/CCNE1 axis. Trends that were observed included upregulation of p130 (in the ESR1 ${ }^{\text {wt }}$ and ESR1 ${ }^{\text {mut }}$ : D538G lines), upregulation of CDK6 (in ESR1 ${ }^{\text {mut }}$ : D538G (except Ribo ${ }^{\mathrm{R}}$ ) and ESR1 ${ }^{\text {mut }}$ : Y537S lines), and upregulation of cyclinD1 (in ESR1 ${ }^{\text {mut }}$ : Y537S lines). Interestingly, a trend towards increased expression of $\mathrm{Rb}(\mathrm{p} R \mathrm{~b})$, phosphorylated $\mathrm{Rb}(\mathrm{p}$ $\mathrm{pRb}$ ) and its family members, and p107 and p130 in the ESR1 ${ }^{\text {wt }}{ }_{- \text {Ribo }^{\mathrm{R}}}$ and ESR1 ${ }^{\mathrm{wt}}$-Abema ${ }^{\mathrm{R}}$ cell lines was observed. CDK2 remained mostly unchanged while cyclin 
D1 and CDK4 showed trends of upregulation in the ESR1 ${ }^{\text {mut }}$ : Y537S cell lines. Cyclin E2 did not show a consistent trend of up- or downregulation in the resistant lines.

Apart from the changes in the expression of key players in the cell cycle pathway, global analysis of RNA sequencing data revealed that the ER pathway, the $\mathrm{NOTCH}$ pathway, and the Wnt pathway, among others, were significantly altered upon long-term palbociclib exposure of the ESR1 ${ }^{\text {wt }}$ line (Fig. 1d).

\section{CDK4/6 inhibitor-resistant models retain ER and ER signaling}

Modulation of ER and ER target genes upon CDK4/6i exposure observed by us (Fig. 1d), and others [25], led us to explore the impact of long-term CDK4/6i exposure on ER and downstream ER signaling targets [progesterone receptor (PR) and growth regulated by estrogen (GREB1)].

In the ESR $1^{\text {wt }}$-Palbo ${ }^{\mathrm{R}}$ cells, a decrease in ER expression was observed; however, the expression of GREB1 remained unaltered. In the ESR $1^{\mathrm{wt}}$-Ribo ${ }^{\mathrm{R}}$, the expression of ER and the target gene GREB1 remained unchanged. While ER protein levels were reduced in the ESR $1^{\mathrm{wt}}$ Abema $^{R}$ cells, GREB1 expression was increased in comparison with the sensitive counterpart (Fig. 2). In the ESR1 $^{\text {mut }}$ : D538G-Palbo ${ }^{\mathrm{R}}$, downregulation of ER was observed; however, the expression of PR, an indicator of active ER signaling, was upregulated. In the ESR1 ${ }^{\text {mut }}$ : D538G-Ribo $^{\mathrm{R}}$ and ESR1 ${ }^{\text {mut }}$ : D538G-Abema ${ }^{\mathrm{R}}$, an upregulation of ER and PR was observed. Overall, in the ESR1 ${ }^{\text {mut }}$ : D538G-CDK4/6i-resistant lines, PR expression was upregulated (Fig. 2). In contrast, in the ESR $1^{\text {mut }}$ : Y537S-Palbo ${ }^{R}$ / Ribo $^{\mathrm{R}} /$ Abema $^{\mathrm{R}}$, a consistent downregulation of PR was observed; however, changes in the ER expression in the resistant lines varied (Fig. 2).

Further evaluation of the ER pathway from the RNA sequencing data described above revealed upregulation of genes such as EGR3 and CAV1 and downregulation of other genes such as $P G R$, in the ESR $1^{\text {wt }}$-Palbo ${ }^{\mathrm{R}}$ cells, highlighting the importance of examining a complete ER-signature (Additional file 1: Figure S2A). The data taken together demonstrate that ER and ER signaling is maintained in models that have been exposed to CDK4/6i.

\section{Elacestrant inhibits growth of CDK4/6i sensitive and resistant lines}

With ER and active ER signaling maintained in the CDK4/ 6i-resistant lines, the relevance of elacestrant treatment in a post-CDK4/6i setting was examined. The sensitive and resistant cell lines were treated with elacestrant, and proliferation was assessed in both a short-term ( 7 days $)$ and a long-term (3-5 weeks) cell assay. Elacestrant inhibited cell growth of the ESR $1^{\mathrm{wt}}$-CDK4/6i-sensitive and ESR $1^{\mathrm{wt}}$ resistant cells. The $\mathrm{EC}_{50}$ values and the extent of growth inhibition were similar regardless of the sensitivity or prior long-term exposure to each CDK4/6i (Fig. 3a). Additionally, despite each resistant cell line showing different levels of ER expression, the response to elacestrant was independent of which CDK4/6i was used to generate resistance (Fig. 3a). A similar observation was made in the ESR1 ${ }^{\text {mut }}$ : D538G and ESR1 ${ }^{\text {mut }}$ : Y537S sensitive and resistant cell lines (Fig. 3a). Overall, elacestrant inhibited the growth of these cells regardless of the sensitivity to CDK4/ 6i and which CDK4/6i they were resistant to. These growth-inhibitory effects were stable and maintained for long durations as demonstrated by the colony formation assays (Fig. 3b).

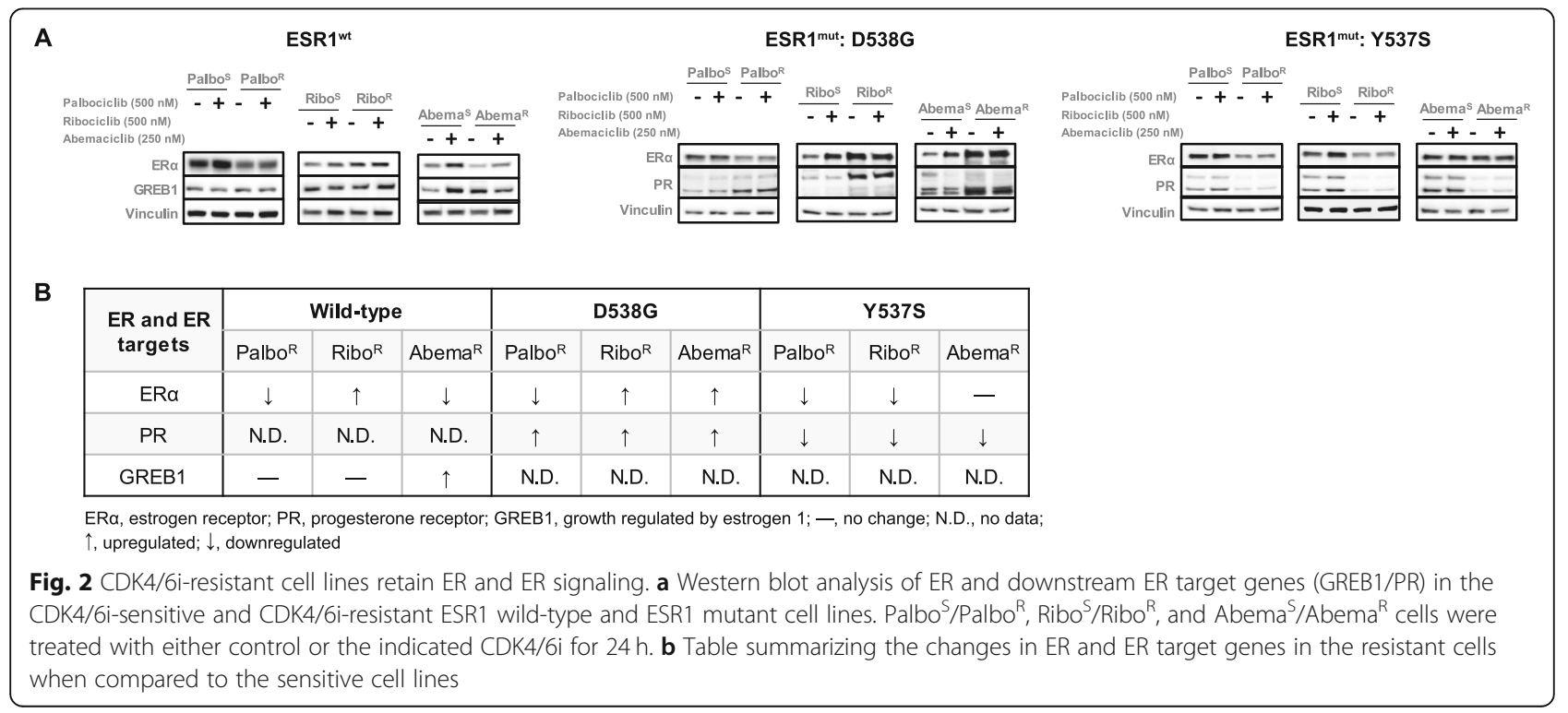




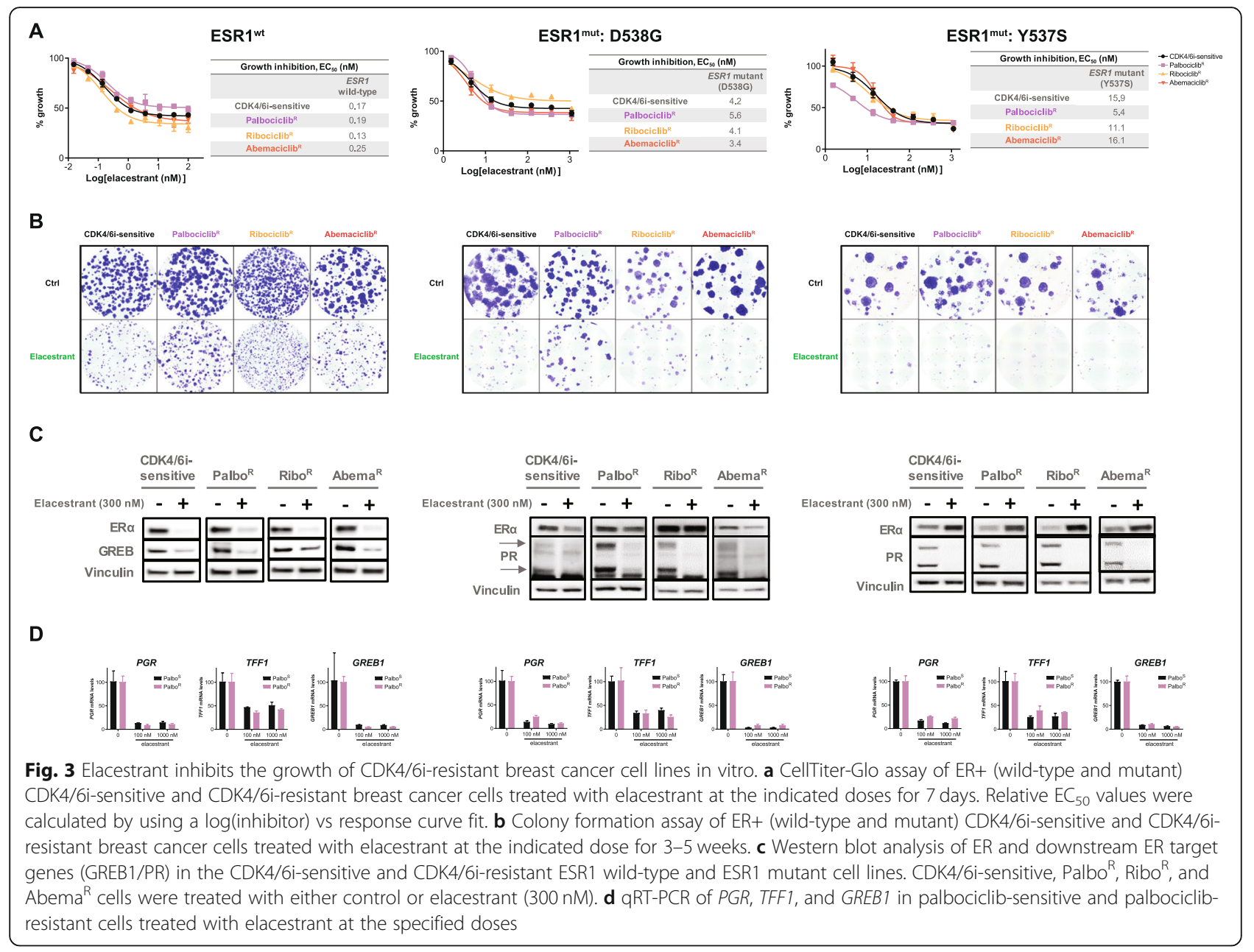

The effects of elacestrant on ER and ER signaling in the sensitive and resistant lines were assessed. Elacestrant degraded ER in the ESR $1^{\text {wt }}$-CDK4/6i sensitive and resistant lines and downregulated GREB1 expression in all these cell lines. In the ESR1 ${ }^{\text {mut }}$ : D538G-CDK4/6i sensitive and resistant lines, a similar downregulation of ER expression was seen with a concurrent downregulation in PR expression. Elacestrant did not degrade ER in our genetically modified ESR1 ${ }^{\text {mut }}$ : Y537S cell lines; however, the downregulation of downstream ER signaling was still observed. Despite the varying effects on ER, a consistent downregulation of GREB1 or PR was observed across all the cell lines, indicating abrogation of ER signaling upon elacestrant treatment (Fig. 3c). Additionally, we examined mRNA levels of PR, TFF1, and GREB1 in all the lines to confirm that this inhibition of ER signaling was not limited to one downstream target. Indeed, we observed downregulation of PR, TFF1, and GREB1 upon elacestrant treatment in all the palbociclib-sensitive and the palbociclib-resistant lines (Fig. 3d). RNA sequencing data from the ESR $1^{\text {wt }}$-Palbo ${ }^{\mathrm{R}}$ cells demonstrated downregulation of additional ER targets, such as
EGR3, upon elacestrant treatment (Additional file 1: Figure S2B).

Taken together, these data demonstrate the antitumor activity of elacestrant in clinically relevant CDK4/ 6i-resistant models in vitro, as well as inhibition of ER signaling and growth, regardless of sensitivity to CDK4/ 6i and ESR1 mutational status.

\section{Elacestrant inhibits growth of PDX models that represent CDK4/6i resistance}

Elacestrant activity was examined in PDX models derived from patients that were either previously treated with and responded to a CDK4/6i or that exhibited de novo resistance to CDK4/6 inhibition. Additionally, a palbociclib-resistant PDX was developed in vivo to model acquired resistance to CDK4/6i in an in vivo setting.

Elacestrant significantly inhibited the growth of PDXR1 tumors harboring wild-type ER (Fig. 4a). A similar extent of growth inhibition was observed with fulvestrant. The PDX was derived from a patient who had progressive disease after being treated with letrozole in 


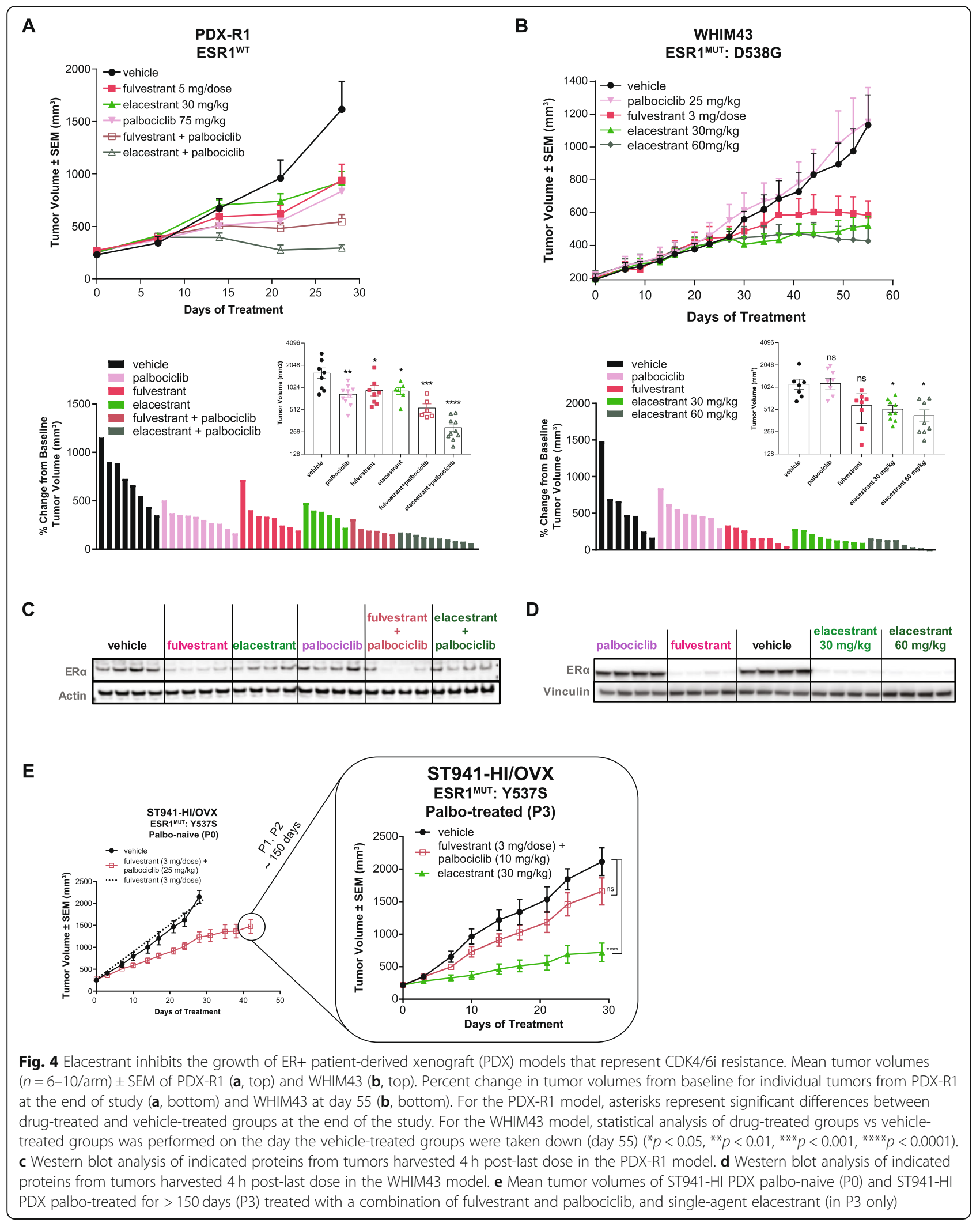


combination with palbociclib for about 14 months. Despite being derived from metastases that progressed on palbociclib, the PDX responded well to palbociclib (Fig. 4a). This could be due to the use of a higher dose of palbociclib than the human equivalent dose (Additional file 1: Figure S4), changes in the molecular characteristics of the tumor before PDX implantation, and/ or the effect of subsequent treatments of the patient, with reversion of the tumor back to palbociclib sensitivity. The combination of palbociclib with elacestrant led to further tumor growth inhibition compared to the combination of palbociclib with fulvestrant (Fig. 4a). Degradation of ER $\alpha$ was observed upon treatment with single-agent elacestrant or fulvestrant, which was maintained upon the combination with palbociclib (Fig. 4c).

The WHIM43 PDX model harbors an ESR1-D538G mutation and has previously been demonstrated to be de novo resistant to palbociclib in vivo [48]. Consistent with this, the lack of $\mathrm{Rb}$ expression, a known mechanism of CDK4/6i resistance, has been reported for this model, which we also confirmed (Additional file 1: Figure S3). Elacestrant demonstrated significant tumor growth inhibition (TGI) at both doses tested while fulvestrant exhibited a non-statistical trend of growth inhibition; this trend did not reach significance when compared to the vehicle control (Fig. 4b). Endof-study tumor analysis revealed degradation of ER by both elacestrant and fulvestrant (Fig. 4d).

The ST941 model has been previously demonstrated to be insensitive to fulvestrant $[49,50]$. We exposed this model to a combination of fulvestrant and palbociclib (P0) (Fig. 4e; fulvestrant data is extrapolated from a separate study) $[49,50]$. Anti-tumor activity observed from the combination (Fig. 4e; left panel) is likely from palbociclib single-agent activity since the model has been shown to be insensitive to fulvestrant [49]. To model fulvestrant and palbociclib resistance, we re-implanted the tumors treated with the combination over two passages (P1, P2) for a total of $>150$ days. In parallel, we assessed the pharmacokinetic properties of palbociclib to determine clinically relevant doses for the evaluation of resistance. In mice, clinically relevant exposure of palbociclib can be achieved at doses between $7.5 \mathrm{mg} / \mathrm{kg}$ and $10 \mathrm{mg} / \mathrm{kg}$, and while $75 \mathrm{mg} / \mathrm{kg}$ or higher of palbociclib is often used in the literature, the exposure achieved at 75 $\mathrm{mg} / \mathrm{kg}$ is likely not achieved in the clinic $(\sim 21 \times$ exposure of approved human dose; Additional file 1: Figure S4). Based on this, we reduced the palbociclib dose to 10 $\mathrm{mg} / \mathrm{kg}$ for the last passage (P3). Elacestrant caused significant TGI in this model despite being exposed to fulvestrant and palbociclib for almost 6 months in vivo, indicating that these tumors retain ER-dependent tumor growth and sensitivity to elacestrant despite continuous exposure to the combination of fulvestrant and palbociclib (Fig. 4e).
Collectively, these data support the anti-tumor activity of elacestrant in models derived from patients that have been treated previously with a CDK4/6i (in combination with an $\mathrm{AI} /$ fulvestrant) and in PDX models that are innately resistant to CDK4/6i.

\section{Compensatory pathway inhibition in combination with endocrine therapy in a post-CDK4/6i setting}

Investigation of combination therapies to combat resistance and target truncal drivers has been on the rise in the metastatic breast cancer setting. One such therapy that has been studied is the combination of alpelisib, a PI3K $\alpha$ inhibitor, with endocrine agents such as letrozole or fulvestrant $[51,52]$. The scientific rationale for this combination is based on the fact that mutations in the PIK3CA gene are frequently present $(\sim 30-40 \%)$ in breast cancer patients [53]. Additionally, a modest enrichment of PIK3CA mutations detected in ctDNA was observed in patients progressing on the combination of fulvestrant and palbociclib in the PALOMA-3 trial [30].

We evaluated inhibitors of the PI3K/mTOR pathway in several PDX models harboring PIK3CA mutations derived from patients treated with a combination of an AI and palbociclib (ST3932 and CTG-2308) or fulvestrant and palbociclib (CTG-2432). The ST3932 model harbored an R88Q mutation in PIK3CA while the CTG2308 models harbored an E545K mutation. The CTG2432 model harbored an E545K and an E722K mutation in the PIK3CA gene and also harbors an E380Q mutation in ESR1. In the ST3932 model, palbociclib did not exhibit significant TGI (Fig. 5a), showing a lack of sensitivity to CDK4/6 inhibition, consistent with the lack of clinical response (Additional file 1: Figure S3B). Evaluation of single-agent elacestrant and the PIK3CA inhibitor alpelisib resulted in significant TGI, demonstrating active growth signals from both the ER and PI3K pathways (Fig. 5a). The combination of elacestrant and alpelisib led to complete TGI, supporting the use of inhibitors of the PI3K pathway in combination therapies in a post-CDK4/6i setting (Fig. 5a). In the CTG-2432 model, palbociclib did not inhibit growth at the clinically achievable dose of $10 \mathrm{mg} / \mathrm{kg}$, demonstrating resistance to CDK4/6 inhibition. It is worthwhile to note that, like the WHIM43 model, analysis of this PDX revealed low levels or a lack of $\mathrm{Rb}$ expression when compared to other sensitive models (Additional file 1: Figure S3A). Singleagent elacestrant demonstrated significant TGI. Everolimus, an inhibitor of mTOR and a downstream effector of PI3K signaling, resulted in partial TGI as a single agent, albeit not to the extent of elacestrant. The combination of elacestrant $(30 \mathrm{mg} / \mathrm{kg})$ and everolimus led to further TGI (Fig. 5b).

In the CTG-2308 model, neither elacestrant nor fulvestrant resulted in significant TGI compared to the 


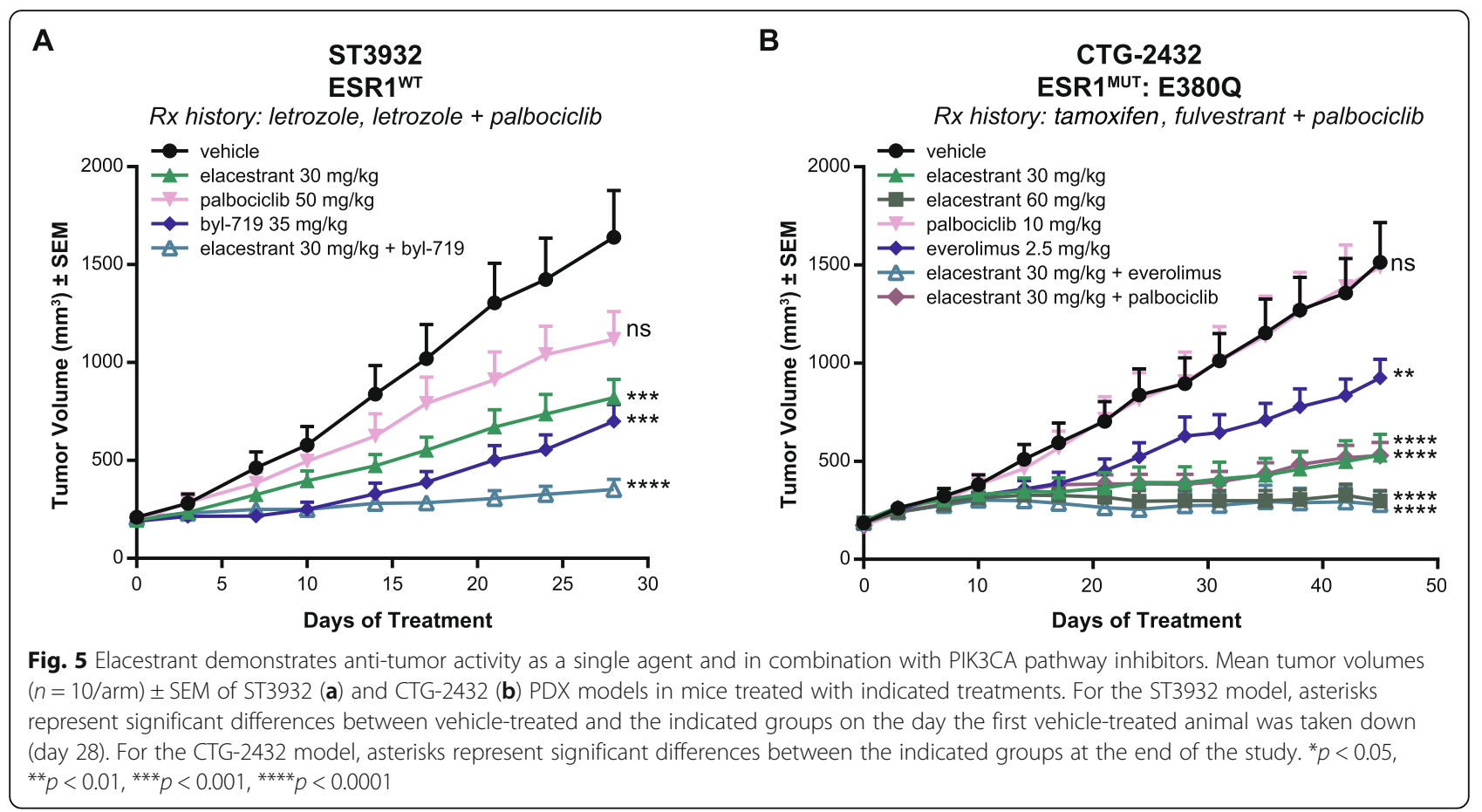

vehicle control (Additional file 1: Figure S5A). The sequencing data of this PDX model revealed the presence of a PIK3CA mutation (data not shown). Everolimus significantly inhibited the growth of this model, suggesting dependence on the PI3K-Akt-mTOR pathway for growth. Phosphorylation of S6, a downstream target of mTOR signaling, was significantly reduced in the everolimus single agent, and elacestrant + everolimus combination arms yet remained relatively unchanged in the elacestrant- or fulvestrant-treated arms (Additional file 1: Figure S5B). Examination of the tumors at the end of the study revealed that ER was degraded and ER signaling was inhibited by both fulvestrant and elacestrant in these tumors (Additional file 1: Figure S5C, S5D); however, this inhibition did not translate to TGI suggesting ER-independent tumor growth. This PDX was sensitive to palbociclib despite being derived from a patient that did not respond clinically to palbociclib (Additional file 1: Figure S3B). Phosphorylated Rb levels were significantly reduced in the palbociclib arms but were unaltered in the elacestrant or fulvestrant arms, which confirms the lack of ER-driven growth of this model.

Taken together, our data demonstrate the anti-tumor activity of elacestrant, as a single agent, and/or in combination with inhibitors of the PI3K/mTOR pathway, in models derived from patients who did not benefit from palbociclib treatment in the clinic.

\section{Elacestrant demonstrates anti-tumor activity in multiple CDK4/6i-resistant settings}

Our in vitro and in vivo PDX models exhibit distinct changes in key cell cycle markers upon continuous exposure to CDK4/6i (Additional file 1: Table S1). Despite the different contexts and molecular changes in each resistant derivative, elacestrant caused significant TGI (Fig. 6a, b), implying prior CDK4/6i treatment did not alter ER-dependent breast cancer cell growth and elacestrant activity in these contexts. In PDX models harboring PIK3CA mutations, the combination of elacestrant and inhibitors of the PI3K pathway led to further TGI (Fig. 6b).

Important cell cycle modulators that contribute to resistance, including those modulated by ER, such as cyclinD1 and E2F1, were examined after the elacestrant treatment in the in vitro and in vivo PDX models. In the ESR1 $^{\text {wt }}$ and ESR1 ${ }^{\text {mut }}$-D538G/Y537S-Palbo ${ }^{\mathrm{R}}$ lines, the downregulation of $\mathrm{p}-\mathrm{pRb}$ was consistently seen across all cell lines after the elacestrant treatment, consistent with the growth inhibition observed. Elacestrant treatment resulted in a downregulation of E2F1 and/or cyclinD1 in most cell lines, suggesting that potent inhibition of ER $\alpha$ can, in turn, inhibit the cyclinD1/CDK4/6/Rb/E2F axis (Fig. 6c).

The observations made in the in vitro resistance lines translated to the long-term in vivo setting (Fig. 6d); the end-of-study analysis of PDX-R1 tumors demonstrated downregulation of E2F1, Rb, cyclinD1, and cyclin E2 after the elacestrant treatment. Similar observations were made in tumors treated with fulvestrant. The combinations of elacestrant or fulvestrant with palbociclib exhibited additional downregulation of E2F1 (Fig. 6d). Significant downregulation of Ki67 was also observed in the combination groups (Fig. 6f). Analogous results were 


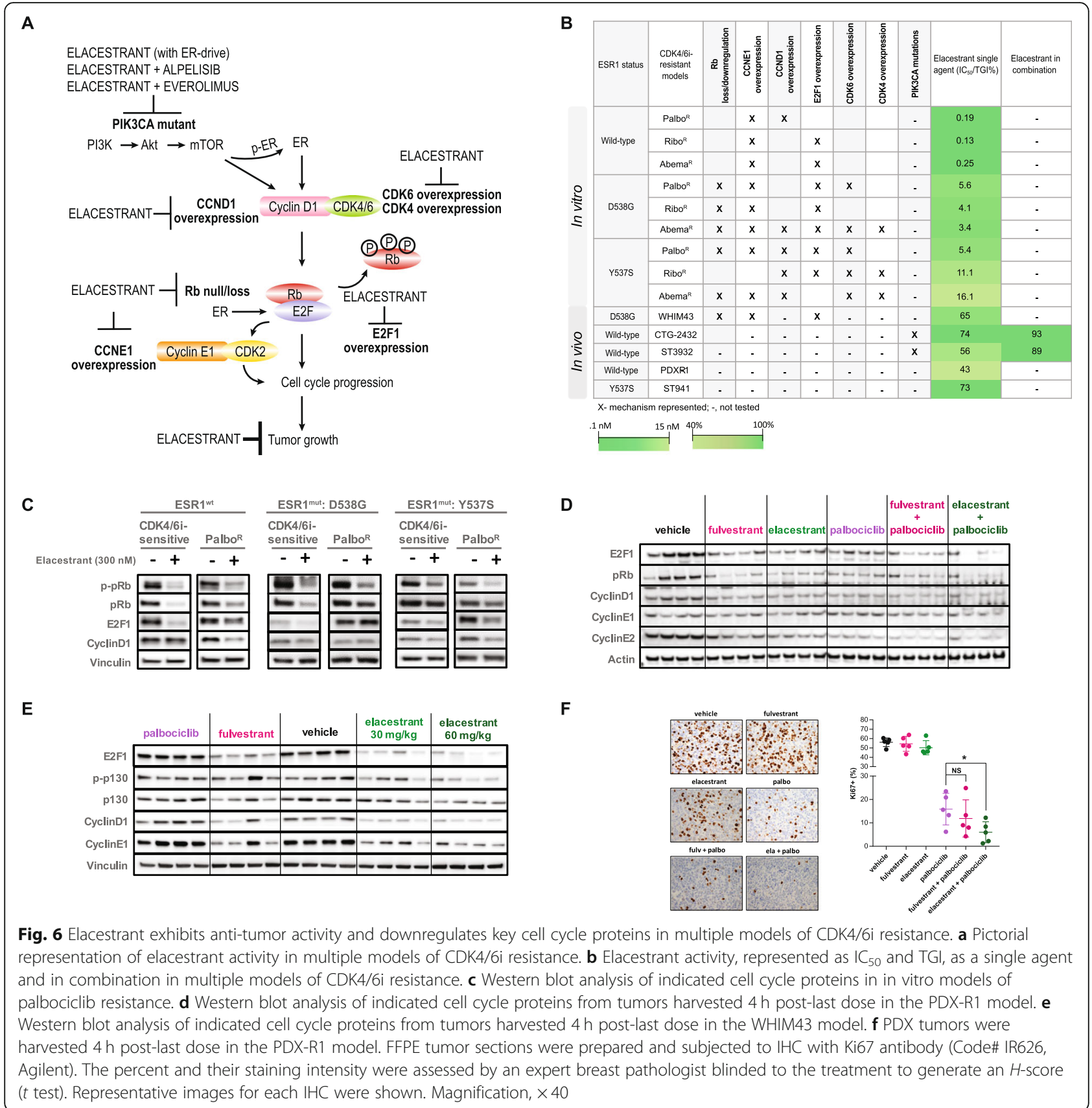

seen in end-of-study tumors from the WHIM43 PDX model. Palbociclib-treated tumors demonstrated no changes in the expression levels of these proteins compared to the vehicle arm, supporting de novo palbociclib resistance seen in the model (Fig. 6e). Elacestrant- and fulvestrant-treated tumors demonstrated reduced expression of E2F1, cyclinD1, and cyclin E1. While the WHIM43 model is Rb-null, it maintains the expression of p130, a member of the Rb family. Elacestrant treatment resulted in reduced expression of phosphorylated p130. This suggests growth in the presence of palbociclib can be mediated by a compensatory family member in an Rb-null background and that elacestrant can inhibit the cell cycle through p130 (Fig. 6e).

Collectively, our data suggest that ER signaling is retained in most models insensitive to CDK4/6 inhibitors. We demonstrate in multiple models of CDK4/6i resistance that elacestrant exhibited anti-tumor activity and this activity was observed despite each resistant model exhibiting differential modulation of key cell cycle proteins. Additionally, elacestrant can serve as an endocrine backbone for PI3K/mTOR inhibitors in a post-CDK4/6i setting. 


\section{Discussion}

Herein, we evaluated the activity of elacestrant, a novel orally bioavailable SERD, in models that represent postCDK4/6i or CDK4/6i-resistant patient populations. With CDK4/6i now a standard-of-care regimen in the $\mathrm{mBC}$ treatment setting, modeling CDK4/6i resistance in order to evaluate subsequent treatment options is vital. We comprehensively studied resistance to all three approved CDK4/6i in both ESR1-WT and mutant tumors. We demonstrate the anti-tumor activity of elacestrant in multiple in vitro models of acquired CDK4/6i resistance that harbored either wild-type or mutant ER $\alpha$ and retained ER-driven tumor growth. Additionally, this anti-tumor activity of elacestrant translates in vivo in multiple PDX models representing innate and acquired CDK4/6i resistance. This preclinical activity, along with the objective responses observed in patients with prior CDK4/6i therapy treated with elacestrant in a phase 1 clinical trial [43], suggests that ER-driven tumor growth can be retained in patients that have been previously treated with CDK4/6i and that the clinical evaluation of an ER-targeted agent, such as elacestrant, is warranted.

Palbociclib, ribociclib, and abemaciclib are currently approved for the treatment of metastatic breast cancer. While the kinome profiles of palbociclib and ribociclib have been shown to overlap to a great extent, abemaciclib has been suggested to target several other CDKs in addition to CDK4/6 [54], which could contribute to greater potency of growth inhibition observed in our models. Several studies have examined resistance to CDK4/6i, either through exposing cells to these inhibitors for months or by overexpressing kinases such as CDK6 to develop resistance [25, 26, 46]. Analogous to these studies, we note an increase in the expression of several cell cycle proteins that are important in the G1-S transition (Additional file 1: Table S1). Our data are consistent with previous preclinical reports of overexpression of cyclin E1, E2F1, cyclinD1, CDK4, and CDK6, and $\mathrm{Rb}$ loss, in models of CDK4/6i resistance $[2,25,26,55,56]$. $\mathrm{Ma}$ et al. demonstrated that E2F target genes, including cyclin E1, were significantly elevated in palbociclib-resistant patient tumors [57]. Gene expression analysis from baseline tumor tissues of the patients from the PALOMA-3 trial revealed that palbociclib efficacy was lower in patients who had higher CCNE1 mRNA expression in metastatic tissue [58]. The authors demonstrated that the "E2F targets" hallmark gene set and high E2F transcriptional activity exhibited the most significant association with a lack of improvement in PFS from the palbociclib combination [58]. Our preclinical observations are in line with these clinical observations with the most-commonly observed mechanism of resistance being cyclin E1 overexpression, likely from increased E2F transcriptional activity (Additional file 1: Table S1). We also observed the overexpression of E2F1 in our models. The role of other players, such as the FAT1/ Hippo pathway which is also known to mediate CDK4/6i resistance [28], is yet to be investigated. It is worth noting that we observe significant anti-tumor activity with elacestrant, even in models such as WHIM43, with increased cyclin E1 expression (Fig. 6b). In fact, high basal expression of cyclin E1 in the palbociclib-resistant WHIM43 PDX (Additional file 1: Figure S2) was reduced upon elacestrant treatment (Fig. 6e). While fulvestrant demonstrated a trend of growth inhibition in this model, this trend did not reach significance. Regardless of the mechanism employed by these tumor cells that leads to an upregulated CCNE1/E2F signature, elacestrant retained anti-tumor activity in in vitro and in in vivo PDX models (Figs. 2, 3, and 4).

ER plays a substantial role in the growth of breast cancer by regulation of cell cycle proteins, such as cyclinD1, E2F1, and c-myc, among others [37, 59-61], and tumor cells resistant to CDK4/6i continue to rely on the ER pathway to drive tumor growth. Indeed, we observed downregulation of cyclinD1, cyclin E1, and E2F1, upon elacestrant treatment in multiple representative models (Fig. 6). It has been previously demonstrated that ER antagonists elicit a distinct, non-overlapping cell cycle arrest program [62]. The growth inhibition activity of elacestrant being maintained in our in vitro models despite prior CDK4/6i exposure could be attributed to this distinct mechanism of cell cycle arrest. A recent retrospective analysis by $\mathrm{Xi}$ et al. demonstrated that hormonal therapy was effective, leading to significant PFS, in patients after palbociclib progression [63]. This supports our preclinical observations that ER signaling, and ER-mediated breast cancer cell growth, is maintained in a post-CDK4/6i setting and warrants the evaluation of elacestrant in patients after disease progression on a CDK4/6 inhibitor.

Higher $\mathrm{IC}_{50}$ 's for ER-targeted agents such as tamoxifen and fulvestrant, and reduced ER and PR expression, have been noted in models of abemaciclib resistance that overexpress CDK6 [25]. While we similarly note increased CDK6 expression in our ESR1-mutant models, this did not confer diminished elacestrant antagonism, possibly due to alternate primary resistance mechanisms driving the growth of the cancer cells in our models. In general, ER signaling was maintained or increased in the ESR $1^{\text {wt }}$ and ESR1 ${ }^{\text {mut }}$ : D538G lines. However, we do observe that not all PDX models derived from patients treated with palbociclib rely on ER signaling to proliferate (e.g., CTG-2308, Additional file 1: Figure S5). For these patients, combinations with targeted therapies might be warranted, and indeed, we demonstrate significant anti-tumor activity when elacestrant is combined with everolimus in the CTG-2308 model (Additional file 1: Figure S5). 
Other sub-clonal populations that were detected in the PALOMA-3 trial included clones containing ESR1 mutations $[30,64]$. Hotspot mutations in the ER ligandbinding domain (LBD), such as the D538G and Y537S, can provide tumor cells a growth advantage, suggesting that these ESR1 mutations, to an extent, may display innate resistance to CDK4/6 inhibitors. This concept has been supported by clinical observations of enrichment or continued selection of ESR1 mutations during combination therapy with palbociclib and letrozole [65]. Additionally, enrichment of the hallmark "E2F targets" pathway, shown to contribute to clinical resistance to palbociclib [58], has been observed in cell lines harboring the Y537S mutation [66]. This mutation has also been previously shown to be resistant to fulvestrant in preclinical reports [67], including our observations where some models that harbor this mutation demonstrate insensitivity to fulvestrant (Fig. 4e) $[42,50]$. Recent clinical evidence confirms these preclinical observations, and indeed, emergence/selection of the Y537S mutation was observed in fulvestrant-treated patients in the PALOMA-3 trial [30]. While fulvestrant lacked efficacy in the ST941 Y537S-mutant model (Fig. 4e) [50], elacestrant significantly inhibited tumor growth. Reasons for this differential activity may include a distinct mechanism of action/PK properties and/or greater target inhibition for this mutation by elacestrant compared to fulvestrant. Moreover, elacestrant caused significant TGI despite $6+$ months of prior treatment with the combination of fulvestrant and palbociclib (Fig. 4e). This suggests, that despite ER-driven tumor growth being maintained in a post-CDK4/6i setting, not all ER antagonists may be able to effectively inhibit growth.

A recent report demonstrated the emergence of $\mathrm{Rb}$ mutations in end-of-treatment samples in a small percentage of patients treated with palbociclib, suggesting the selection of these mutations during treatment [30]. The authors highlight the sub-clonal nature of these $\mathrm{Rb}$ mutations compared to parallel detection of much higher allele fractions of the PIK3CA mutation, suggesting the truncal nature of PIK3CA clones. PIK3CA mutations are found in $\sim 30-40 \%$ of breast cancer patients $[53,68,69]$. In the SOLAR-1 trial, the addition of alpelisib, a PIK3CA inhibitor, to fulvestrant prolonged PFS [70]. Additionally, a triple combination of CDK4/6i, endocrine therapy, and a PIK3CA inhibitor is currently being evaluated (NCT02088684). Whether the emergence of $\mathrm{Rb}$ mutations or increased allele frequency of PIK3CA mutants contributes to CDK4/6i resistance in our models has yet to be determined. Regardless, we demonstrate that elacestrant inhibits growth in models with upregulated, downregulated $\mathrm{Rb}$ or $\mathrm{Rb}$-null cells and is able to produce significant TGI in models with ER-driven tumor cell growth and PIK3CA mutations (Figs. 3, 4, and 5). Similar to the SOLAR-1 trial (NCT02437318) [70] and previous preclinical observations [26], combining an endocrine agent, such as elacestrant, with alpelisib in the ST3932 model harboring a PIK3CA mutation resulted in further TGI (Fig. 5).

The data presented here demonstrate that employing an ER-targeted therapy is a relevant strategy to evaluate in a post-CDK4/6i setting. Elacestrant, a novel orally bioavailable SERD, significantly inhibits ER-mediated growth in clinically relevant in vitro and patient-derived models of CDK4/6i resistance. Additionally, elacestrant can serve as an endocrine backbone to combination therapies that target known driver pathways. These data provide a scientific rationale for the clinical investigation of elacestrant in a post-CDK4/6i patient population irrespective of ESR1 mutational status.

\section{Conclusions}

With CDK4/6 inhibitors being an integral component in the treatment of metastatic breast cancer, it has become increasingly important to understand the impact of these inhibitors on the molecular characteristics of the tumor and, subsequently, second- and third-line treatment options. We demonstrate in preclinical cell line and patient-derived xenograft models that ER signaling mediated breast cancer cell growth is maintained in most settings despite de novo or acquired resistance to CDK4/6 inhibitors. Elacestrant, an oral SERD, inhibits ER signaling and growth of these CDK4/6i-resistant breast tumor cells. Additionally, elacestrant can combine with approved inhibitors of alternate driver pathways to further inhibit breast cancer cell growth. These preclinical findings warrant the clinical investigation of elacestrant in patients after progression on a CDK4/6i.

\section{Supplementary information}

Supplementary information accompanies this paper at https://doi.org/10 1186/s13058-019-1230-0.

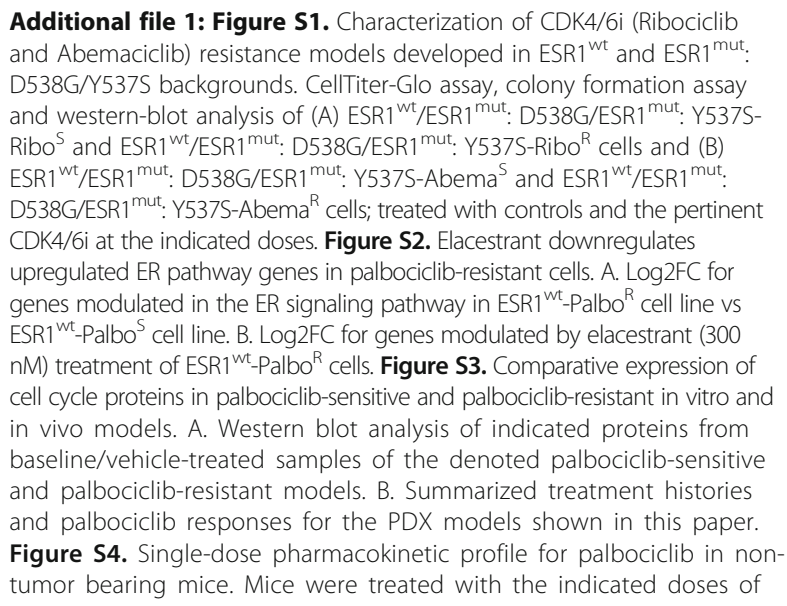
D538G/Y537S backgrounds. CellTiter-Glo assay, colony formation assay

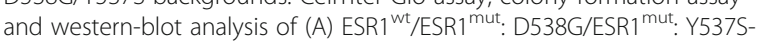
Ribo $^{\text {S }}$ and ESR1 ${ }^{\text {wt }} /$ ESR $^{\text {mut. D538G/ESR1 }}{ }^{\text {mut: }}$. Y537S-Ribo ${ }^{R}$ cells and (B) ESR1 ${ }^{\text {wt }} /$ ESR1 ${ }^{\text {mut }}$ : D538G/ESR1 ${ }^{\text {mut: }}$ Y537S-Abema ${ }^{\text {S }}$ and ESR1 ${ }^{\text {wt }} /{ }^{\text {ESR }} 1^{\text {mut: }}$ : D538G/ESR1 ${ }^{\text {mut }}$ : Y537S-Abema ${ }^{\mathrm{R}}$ cells; treated with controls and the pertinent CDK4/6i at the indicated doses. Figure S2. Elacestrant downregulates upregulated ER pathway genes in palbociclib-resistant cells. A. Log2FC for genes modulated in the ER signaling pathway in ESR1 ${ }^{\text {wt }}$-Palbo ${ }^{R}$ cell line vs ESR1 ${ }^{\text {wt }}$-Palbo ${ }^{\text {S }}$ cell line. B. Log2FC for genes modulated by elacestrant (300 $n M$ ) treatment of ESR $1^{\text {wt }}$-Palbo ${ }^{R}$ cells. Figure S3. Comparative expression of cell cycle proteins in palbociclib-sensitive and palbociclib-resistant in vitro and in vivo models. A. Western blot analysis of indicated proteins from baseline/vehicle-treated samples of the denoted palbociclib-sensitive and palbociclib-resistant models. B. Summarized treatment histories and palbociclib responses for the PDX models shown in this paper. Figure S4. Single-dose pharmacokinetic profile for palbociclib in nontumor bearing mice. Mice were treated with the indicated doses of 
palbociclib and plasma collected at the indicated timepoints after single dose. Mean concentration \pm SD of palbociclib is depicted ( $n=$ 4/timepoint/dose). Area under the curve $\left(A \cup C_{0 \text {-inf }}\right)$ was calculated and divided by the $\mathrm{AUC}_{0 \text {-inf }}$ for the clinical regimen of palbociclib (lbrance-125 mg). Figure S5. ER-independent growth of PDX model previously treated with $\mathrm{Al}+$ palbociclib. A. Mean tumor volume of CTG-2308 PDX model, asterisks represent differences between the indicated groups at the end-of-study; $p$-values $*, p<0.05, * *, p<0.01$, *** $p<0.001,{ }^{* * * *}, p<0.0001$. B. Western blot analysis of phospho-RB and RB from tumors harvested $4 \mathrm{~h}$ post-last dose. C. Western-blot analysis of indicated proteins from tumors harvested 4 h post-last dose for the indicated treatment arms. D. qRT-PCR analysis of PGR, TFF1, and GREB1 in end-of-study tumors treated with the elacestrant and fulvestrant. Table S1. Commonly observed mechanisms upregulated in CDK4/6i-resistance models include CCNE1 and E2F1 overexpression. Summarized results from Fig. 2 demonstrating modulation of cell cycle proteins in our in vitro models resistant to palbociclib, ribociclib, and abemaciclib.

\section{Abbreviations}

Al: Aromatase inhibitor; AUC: Area under the curve; ctDNA: Circulating tumor DNA; CDK2/4/6: Cyclin-dependent kinase 2/4/6; CDK4/6i: Cyclin-dependent kinase 4/6 inhibitors; EGR3: Early growth response 3; E2F: E2 factor: ER: Estrogen receptor; ESR1: Estrogen receptor alpha gene; GREB1: Growth regulated by estrogen in breast cancer 1 ; IHC: Immunohistochemistry; LBD: Ligand-binding domain; LTED: Long-term estrogen deprived; PALOMA3: Palbociclib (PD-0332991) Combined with Fulvestrant In Hormone Receptor+ HER2-Metastatic Breast Cancer After Endocrine Failure; PDX: Patient-derived xenograft; PGR: Progesterone receptor; RTQPCR: Quantitative reverse transcriptase polymerase chain reaction; pRb/ $\mathrm{Rb}$ : Retinoblastoma protein; SERD: Selective estrogen receptor degrader; SERM: Selective estrogen receptor modulator; SOLAR-1: Study Assessing the Efficacy and Safety of Alpelisib Plus Fulvestrant in Men and Postmenopausal Women with Advanced Breast Cancer Which Progressed on or After Aromatase Inhibitor Treatment; TFF1: Trefoil factor 1; \%TGI: Percent tumor growth inhibition

\section{Acknowledgements}

Graphic services were provided by Phillips Gilmore Oncology Communications, Inc., funded by Radius Health, Inc. on behalf of its wholly owned subsidiary, Radius Pharmaceuticals, Inc.

\section{Authors' contributions}

HP and TB were responsible for the concept and design of the study. HP, NT, $\mathrm{KL}, \mathrm{MH}, \mathrm{HA}$, and TM contributed substantially to the acquisition of the data. $H P, N T, K L, M H, S T, C A$, and TB contributed to the analysis and interpretation of the data. HP, with supervision from $T B$, drafted the manuscript. All authors critically reviewed the manuscript for important intellectual content and approved the final version.

\section{Funding}

This study was funded by Radius Health, Inc. on behalf of its wholly owned subsidiary, Radius Pharmaceuticals, Inc.

\section{Availability of data and materials}

The datasets used and/or analyzed during the current study are available from the corresponding author on reasonable request.

\section{Ethics approval and consent to participate}

All study protocols were reviewed by Radius, approved by Institutional Animal Care and Use Committees (IACUC), and conducted in accordance with the US and International regulations for the protection of laboratory animals.

\section{Consent for publication}

N/A

\section{Competing interests}

H Patel, N Tao, H Arlt, T Mullarkey, S Troy, and T Bihani are employees and shareholders of Radius Health, Inc. CL Arteaga has received research grants from Puma Biotechnology, Pfizer, Lilly, Bayer, Takeda, and Radius. He holds stock options in Provista and Y-TRAP and serves in an advisory role to Novartis, Merck, Lilly, Symphogen, Daiichi Sankyo, Radius, Taiho Oncology, H3Biomedicine, OrigiMed, Puma Biotechnology, and Sanofi. He is a member of the Scientific Advisory Board (SAB) of the Komen Foundation. All other authors declare that they have no competing interests.

\section{Author details}

${ }^{1}$ Radius Health, Inc., 950 Winter St., Waltham, MA 02451, USA. ${ }^{2}$ UT Southwestern Simmons Cancer Center, 5323 Harry Hines Blvd., Dallas, TX 75390, USA.

Received: 16 September 2019 Accepted: 15 November 2019 Published online: 18 December 2019

\section{References}

1. SEER Cancer Stat Facts: Female Breast Cancer. https://seer.cancer.gov/ statfacts/html/breast.html

2. Pandey K, An HJ, Kim SK, et al. Molecular mechanisms of resistance to CDK4/6 inhibitors in breast cancer: a review. Int J Cancer. 2018. https://doi.org/10.1002/ijc.32020.

3. Anderson $\mathrm{E}$. The role of oestrogen and progesterone receptors in human mammary development and tumorigenesis. Breast Cancer Res. 2002;4:197-201.

4. Cordera F, Jordan VC. Steroid receptors and their role in the biology and control of breast cancer growth. Semin Oncol. 2006;33:631-41.

5. Finn RS, Martin M, Rugo HS, Jones S, Im SA, Gelmon K, Harbeck N, Lipatoy ON, Walshe JM, Moulder S, Gauthier E, Lu DR, Randolph S, Dieras V, Slamon DJ. Palbociclib and letrozole in advanced breast cancer. N Engl J Med. 2016;375:1925-36

6. Baumann CK, Castiglione-Gertsch M. Clinical use of estrogen receptor modulators and down regulators with the main focus on breast cancer. Minerva Ginecol. 2009;61:517-39.

7. McDonnell DP, Wardell SE. The molecular mechanisms underlying the pharmacological actions of ER modulators: implications for new drug discovery in breast cancer. Curr Opin Pharmacol. 2010;10:620-8.

8. Avvaru SP, Noolvi MN, Aminbhavi TM, Chkraborty S, Dash A, Shukla SS. Aromatase inhibitors evolution as potential class of drugs in the treatment of postmenopausal breast cancer women. Mini Rev Med Chem. 2018;18: 609-21.

9. Patel HK, Bihani T. Selective estrogen receptor modulators (SERMs) and selective estrogen receptor degraders (SERDs) in cancer treatment. Pharmacol Ther. 2018;186:1-24.

10. Dodwell D, Wardley A, Johnston S. Postmenopausal advanced breast cancer: options for therapy after tamoxifen and aromatase inhibitors. Breast. 2006;15:584-94.

11. Zheng WQ, Lu J, Zheng JM, Hu FX, Ni CR. Variation of ER status between primary and metastatic breast cancer and relationship to p53 expression. Steroids. 2001;66:905-10.

12. Loibl S, Turner NC, Ro J, Cristofanilli M, Iwata H, Im SA, Masuda N, Loi S, Andre F, Harbeck N, Verma S, Folkerd E, Puyana Theali K, Hoffman J, Zhang $\mathrm{K}$, Bartlett $\mathrm{CH}$, Dowsett M. Palbociclib combined with fulvestrant in premenopausal women with advanced breast cancer and prior progression on endocrine therapy: PALOMA-3 results. Oncologist. 2017;22:1028-38.

13. Hortobagyi GN, Stemmer SM, Burris HA, Yap YS, Sonke GS, Paluch-Shimon S, Campone $\mathrm{M}$, Blackwell KL, André F, Winer EP, Janni W, Verma S, Conte P, Arteaga $\mathrm{CL}$, Cameron DA, Petrakova K, Hart LL, Villanueva C, Chan A, Jakobsen E, Nusch A, Burdaeva O, Grischke EM, Alba E, Wist E, Marschner N, Favret YD, Bachelot T, Tseng LM, Blau S, Xuan F, Souami F, Miller M, Germa C, Hirawat S, O'Shaughnessy J. Ribociclib as first-line therapy for HR-positive, advanced breast cancer. N Engl J Med. 2016;375:1738-48.

14. Sonke GS, Hart LL, Campone M, Erdkamp F, Janni W, Verma S, Villanueva C, Jakobsen E, Alba E, Wist E, Favret AM, Bachelot T, Hegg R, Wheatley-Price P, Souami F, Sutradhar S, Miller M, Germa C, Burris HA. Ribociclib with letrozole vs letrozole alone in elderly patients with hormone receptor-positive, HER2negative breast cancer in the randomized MONALEESA-2 trial. Breast Cancer Res Treat. 2018;167:659-69.

15. Sledge GW, Toi M, Neven P, Sohn J, Inoue K, Pivot X, Burdaeva O, Okera M, Masuda N, Kaufman PA, Koh H, Grischke EM, Frenzel M, Lin Y, Barriga S, Smith IC, Bourayou N, Llombart-Cussac A. MONARCH-2: abemaciclib in combination with fulvestrant in women with HR+/HER2 - advanced breast 
cancer who had progressed while receiving endocrine therapy. J Clin Oncol. 2017:35:2875-84.

16. Goetz MP, Toi M, Campone M, Sohn J, Paluch-Shimon S, Huober J, Park IH, Tredan O, Chen SC, Manso L, Freedman OC, Garnica Jaliffe G, Forrester T, Frenzel M, Barriga S, Smith IC, Bourayou N, Di Leo A. MONARCH-3: abemaciclib as initial therapy for advanced breast cancer. J Clin Oncol. 2017; 35:3638-46.

17. Johnston S, Martin M, Di Leo A, Im SA, Awada A, Forrester T, Frenzel M, Hardebeck MC, Cox J, Barriga S, Toi M, Iwata H, Goetz MP. MONARCH 3 final PFS: a randomized study of abemaciclib as initial therapy for advanced breast cancer. NPJ Breast Cancer. 2019;5:5.

18. Ibrance [package insert]. New York: Pfizer; 2018. http://labeling.pfizer.com/ ShowLabeling.aspx?id=2191. Accessed 15 Aug 2019.

19. Kisqali [package insert]. East Hanover: Novartis; 2018. https://www.pharma. us.novartis.com/sites/www.pharma.us.novartis.com/files/kisqali.pdf.

20. Verzenio [package insert]. Indianapolis, IN: Eli Lilly; 2018. http://uspl.lilly.com/ verzenio/verzenio.html\#pi. Accessed 15 Aug 2019.

21. Turner NC, Slamon DJ, Ro J, Bondarenko I, Im SA, Masuda N, Colleoni M, DeMichele A, Loi S, Verma S, Iwata H, Harbeck N, Loibl S, André F, Puyana Theall K, Huang X, Giorgetti C, Huang Bartlett C, Cristofanilli M. Overall survival with palbociclib and fulvestrant in advanced breast cancer. N Engl J Med. 2018;379:1926-36.

22. Slamon DJ, Neven $\mathrm{P}$, Chia S, Fasching PA, De Laurentiis M, Im S-A, Petrakova K, Bianchi GV, Esteva FJ, Martin M, Nusch A, Sonke GS, De la Cruz-Merino L, Beck JT, Pivot X, Sondhi M, Wang Y, Chakravartty A, Rodriguez-Lorenc K, Jerusalem G. Overall survival (OS) results of the phase III MONALEESA-3 trial of postmenopausal patients (pts) with hormone receptorpositive (HR+), human epidermal growth factor 2-negative (HER2-) advanced breast cancer (ABC)treated with fulvestrant (FUL) \pm ribociclib (RIB). Annal Oncol. 2019;30:https://doi.org/10.1093/annonc/mdz394.007.

23. Lu Y-S, Bardia A, Vázquez RV, Colleoni MA, Wheatley-Price P, Im Y-H, Babu G, Tripathy D, Lanoue BR, Chandiwana D, Ridolfi A, Hughes G, Zarate JP, Gounaris I, Harbeck N. Updated overall survival (OS) and quality of life (QoL) in premenopausal patients (pts) with advanced breast cancer (ABC) who received ribociclib (RIB) or placebo (PBO) plus goserelin and a nonsteroidal aromatase inhibitor (NSAl) in the MONALEESA-7 (ML-7) trial. Ann Oncol. 2019;30:v106.

24. Sledge GW Jr, Toi M, Neven P, Sohn J, Inoue K, Pivot X, Burdaeva O, Okera M, Masuda N, Kaufman PA, Koh H, Grischke EM, Conte P, Lu Y, Barriga S, Hurt K, Frenzel M, Johnston S, Llombart-Cussac A. The effect of abemaciclib plus fulvestrant on overall survival in hormone receptor-positive, ERBB2negative breast cancer that progressed on endocrine therapy-MONARCH 2: a randomized clinical trial. JAMA Oncol. 2019. https://doi.org/10.1001/ jamaoncol.2019.4782 [Epub ahead of print].

25. Yang C, Li Z, Bhatt T, Dickler M, Giri D, Scaltriti M, Baselga J, Rosen N, Chandarlapaty S. Acquired CDK6 amplification promotes breast cancer resistance to CDK4/6 inhibitors and loss of ER signaling and dependence. Oncogene. 2017;36:2255-64.

26. Herrera-Abreu MT, Palafox M, Asghar U, Rivas MA, Cutts RJ, Garcia-Murillas I, Pearson A, Guzman M, Rodriguez O, Grueso J, Bellet M, Cortes J, Elliot R, Pancholi S, Baselga J, Dowsett M, Martin LA, Turner NC, Serra V. Early adaptation and acquired resistance to CDK4/6 inhibition in estrogen receptor-positive breast cancer. Cancer Res. 2016;76:2301-13.

27. Dean JL, Thangavel C, McClendon AK, Reed CA, Knudsen ES. Therapeutic CDK4/6 inhibition in breast cancer: key mechanisms of response and failure. Oncogene. 2010;29:4018-32.

28. Li Z, Razavi P, Li Q, Toy W, Liu B, Ping C, Hsieh W, Sanchez-Vega F, Brown DN, Da Cruz Paula AF, Morris L, Selenica P, Eichenberger E, Shen R, Schultz N, Rosen N, Scaltriti M, Brogi E, Baselga J, Reis-Filho JS. Chandarlapaty S1. Loss of the FAT1 tumor suppressor promotes resistance to CDK4/6 inhibitors via the Hippo pathway. Cancer Cell. 2018;34:893-905.

29. Condorelli R, Spring L, O'Shaughnessy J, Lacroix L, Bailleux C, Scott V, Dubois J, Nagy RJ, Lanman RB, lafrate AJ, Andre F, Bardia A. Polyclonal RB1 mutations and acquired resistance to CDK 4/6 inhibitors in patients with metastatic breast cancer. Ann Oncol. 2018;29:640-5.

30. O'Leary B, Cutts RJ, Liu Y, Hrebien S, Huang X, Fenwick K, Andre F, Loibl S, Loi S, Garcia-Murillas I, Cristofanilli M, Huang-Bartlett C, Turner NC. The genetic landscape and clonal evolution of breast cancer resistance to palbociclib plus fulvestrant in the PALOMA-3 trial. Cancer Discov. 2018;8: 1390-403.
31. Berge EO, Knappskog S, Geisler S, Staalesen V, Pacal M, Børreson-Dale AL, Puntervoll P, Lillehaug JR, Lønning PE. Identification and characterization of retinoblastoma gene mutations disturbing apoptosis in human breast cancers. Mol Cancer. 2010;9:173. https://doi.org/10.1186/1476-4598-9-173.

32. Berge EO, Knappskog S, Lillehaug JR, Lønning PE. Alterations of the retinoblastoma gene in metastatic breast cancer. Clin Exp Metastasis. 2011;28:319-26

33. Ciriello G, Gatza ML, Beck AH, Wilkerson MD, Rhie SK, Pastore A, Zhang H, McLellan M, Yau C, Kandoth C, Bowlby R, Shen H, Hayat S, Fieldhouse R, Lester SC, Tse GM, Factor RE, Collins LC, Allison KH, Chen YY, Jensen K, Johnson NB, Oesterreich S, Mills GB, Cherniack AD, Robertson G, Benz C, Sander C, Laird PW, Hoadley KA, King TA, TCGA Research Network, Perou $\mathrm{CM}$. Comprehensive molecular portraits of invasive lobular breast cancer. Cell. 2015;163:506-19.

34. Sabbah M, Courilleau D, Mester J, Redeuilh G. Estrogen induction of the cyclin D1 promoter: involvement of a CAMP response-like element. Proc Natl Acad Sci U S A. 1999:96:11217-22.

35. Lange CA, Yee D. Killing the second messenger: targeting loss of cell cycle control in endocrine-resistant breast cancer. Endocr Relat Cancer. 2011;18: C19-24.

36. He X, Xiang H, Zong X, Yan X, Yu Y, Liu G, Zou D, Yang H. CDK2-AP1 inhibits growth of breast cancer cells by regulating cell cycle and increasing docetaxel sensitivity in vivo and in vitro. Cancer Cell Int. 2014;14:130. https://doi.org/10.1186/s12935-014-0130-8.

37. Wang W, Dong L, Saville B, Safe S. Transcriptional activation of E2F1 gene expression by 17beta-estradiol in MCF-7 cells is regulated by NF-Y-Sp1/ estrogen receptor interactions. Mol Endocrinol. 1999;13:1373-87.

38. Miller TW, Balko JM, Fox EM, Ghazoui Z, Dunbier A, Anderson H, Dowsett M, Jiang A, Smith RA, Maira SM, Manning HC, González-Angulo AM, Mills GB, Higham C, Chanthaphaychith S, Kuba MG, Miller WR, Shyr Y, Arteaga CL. ERa-dependent E2F transcription can mediate resistance to estrogen deprivation in human breast cancer. Cancer Discov. 2011;1:338-51.

39. Robertson JF. Fulvestrant (Faslodex) - how to make a good drug better. Oncologist. 2007;12:774-84.

40. McDonnell DP, Wardell SE, Norris JD. Oral selective estrogen receptor downregulators (SERDs), a breakthrough endocrine therapy for breast cancer. J Med Chem. 2015;58:4883-7.

41. Garner F, Shomali M, Paquin D, Lyttle CR, Hattersley G. RAD1901:a novel, orally bioavailable selective estrogen receptor degrader that demonstrates antitumor activity in breast cancer xenograft models. Anti-Cancer Drugs. 2015;26:948-56.

42. Bihani T, Patel HK, Arlt H, Tao N, Jiang H, Brown JL, Purandare DM, Hattersley G, Garner F. Elacestrant (RAD1901), a selective estrogen receptor degrader (SERD), has antitumor activity in multiple ER+ breast cancer patient-derived xenograft models. Clin Cancer Res. 2017;23:4793-804.

43. Bardia A, Kabos P, Elledge R, Wang D, Shen J, Garner F. Evaluation of RAD1901, a novel investigational, selective estrogen receptor degrader (SERD), for the treatment of ER-positive (ER+) advanced breast cancer. DOI: https://doi.org/10.1200/JCO.2017.35.15_suppl.1014 J Clin Oncol. 35, no. 15_ suppl (May 20, 2017) 1014-1014.

44. Bardia A, Aftimos P, Bihani T, Anderson-Villaluz AT, Jung J, Conlan MG, Kaklamani VG. EMERALD: phase III trial of elacestrant (RAD1901) vs endocrine therapy for previously treated ER+ advanced breast cancer. Future Oncol. 2019. https://doi.org/10.2217/fon-2019-0370 [Epub ahead of print].

45. de Leeuw R, McNair C, Schiewer MJ, Neupane NP, Brand LJ, Augello MA, Li Z, Cheng LC, Yoshida A, Courtney SM, Hazard ES, Hardiman G, Hussain MH, Diehl JA, Drake JM, Kelly WK, Knudsen KE. MAPK reliance via acquired CDK4/ 6 inhibitor resistance in cancer. Clin Cancer Res. 2018;24:4201-14.

46. Jansen VM, Bhola NE, Bauer JA, Formisano L, Lee KM, Hutchinson KE, Witkiewicz AK, Moore PD, Estrada MV, Sánchez V, Ericsson PG, Sanders ME, Pohlmann PR, Pishvaian MJ, Riddle DA, Dugger TC, Wei W, Knudsen ES, Arteaga CL. Kinome-wide RNA interference screen reveals a role for PDK1 in acquired resistance to CDK4/6 inhibition in ER-positive breast cancer. Cancer Res. 2017:77:2488-99.

47. Livak KJ, Schmittgen TD. Analysis of relative gene expression data using real-time quantitative $P C R$ and the 2(-delta delta $C(T))$ method. Methods. 2001;25:402-8.

48. Wardell SF, Ellis MJ, Alley HM, Eisele K, VanArsdale T, Dann SG, Arndt KT, Primeau T, Griffin E, Shao J, Crowder R, Lai JP, Norris JD, McDonnell JP, Li S. Efficacy of SERD/SERM hybrid -CDK4/6 inhibitor combinations in models of endocrine therapy-resistant breast cancer. Clin Cancer Res. 2015;21:5121-30. 
49. Patel HK, Tao J, Heike A, Bihani T. Anti-tumor activity of elacestrant (RAD1901) in models harboring ESR1 mutations resistant to standard care of therapies. Poster presented at: 2018 San Antonio Breast Cancer Symposium (SABCS); December 4-8, 2018; San Antonio, TX, USA. Abstract P6-20-08.

50. Bihani T, Arlt H, Brechbuhl H, Patel H, Tao N, Purandare DM, Hattersley G, Kabos P, Garner F. RAD1901 demonstrates anti-tumor activity in multiple models of ER-positive breast cancer treatment resistance. Cancer Res. 2017; 77:P3-04. https://doi.org/10.1158/1538-7445.SABCS16-P3-04-22.

51. André F, Ciruelos E, Rubovszky G, Campone M, Loibl S, Rugo HS, Iwata H, Conte P, Mayer IA, Kaufman B, Yamashita T, Lu YS, Inoue K, Takahashi M, Pápai Z, Longin AS, Mills D, Wilke C, Hirawat S, Juric D, SOLAR-1 Study Group. Alpelisib for PIK3CA-mutated, hormone receptor-positive advanced breast cancer. N Engl J Med. 2019;380:1929-40.

52. Mayer IA, Abramson VG, Formisano L, Balko JM, Estrada MV, Sanders ME, Juric D, Solit D, Berger MF, Won HH, Li Y, Cantley LC, Winer E, Arteaga CL. A phase Ib study of alpelisib (BYL719), a PI3Ka-specific inhibitor, with letrozole in ER+/HER2- metastatic breast cancer. Clin Cancer Res. 2017:23:26-34.

53. Kratz J, Burkard M, O'Meara T, Pusztai L, Veitch Z, Bedard PL. Incorporating genomics into the care of patients with advanced breast cancer. Am Soc Clin Oncol Educ Book. 2018;38:56-64.

54. Hafner M, Mills CE, Subramanian K, Chen C, Chung M, Boswell SA, Everley RA, Liu C, Walmsley CS, Juric D, Sorger PK. Multi-omics profiling establishes the polypharmacology of FDA approved CDK4/6 inhibitors and the potential for differential clinical activity. doi: https://doi.org/10.1101/211680.

55. Cornell L, Wander SA, Visal T, Wagle N, Shapiro GI. MicroRNA-mediated suppression of the TGF- $\beta$ pathway confers transmissible and reversible CDK4/6 inhibitor resistance. Cell Rep. 2019;26:2667-80.

56. Guarducci C, Bonechi M, Benelli M, Biagioni C, Boccalini G, Romagnoli D, Verardo R, Schiff R, Osborne CK, De Angelis C, Di Leo A, Malorni L, Migliaccio I. Cyclin E1 and Rb modulation as common events at time of resistance to palbociclib in hormone receptor-positive breast cancer. NPJ Breast Cancer. 2018;4:38. https://doi.org/10.1038/s41523-018-0092-4.

57. Ma CX, Gao F, Luo J, Northfelt DW, Goetz M, Forero A, Hoog J, Naughton M, Ademuyiwa F, Suresh R, Anderson KS, Margenthaler J, Aft R, Hobday T, Moynihan T, Gillanders W, Cyr A, Eberlein TJ, Hieken T, Krontiras H, Guo Z, Lee MV, Spies NC, Skidmore ZL, Griffith OL, Griffith M, Thomas S, Bumb C, Vij K, Bartlett CH, Koehler M, Al-Kateb H, Sanati S, Ellis MJ. NeoPalAna: neoadjuvant palbociclib, a cyclin-dependent kinase 4/6 inhibitor, and anastrozole for clinical stage 2 or 3 estrogen receptor-positive breast cancer. Clin Cancer Res. 2017;23:4055-65.

58. Turner NC, Liu Y, Zhu Z, Loi S, Colleoni M, Loibl S, DeMichele A, Harbeck N, André F, Bayar MA, Michiels S, Zhang Z, Giorgetti C, Arnedos M, Huang Bartlett C, Cristofanilli M. Cyclin E1 expression and palbociclib efficacy in previously treated hormone receptor-positive metastatic breast cancer. J Clin Oncol. 2019;37:1169-78.

59. Ngwenya S, Safe S. Cell context-dependent differences in the induction of E2F-1 gene expression by 17 beta-estradiol in MCF-7 and ZR-75 cells. Endocrinology. 2003;144:1675-85.

60. Doisneau-Sixou SF, Sergio CM, Carroll JS, Hui R, Musgrove EA, Sutherland RL Estrogen and antiestrogen regulation of cell cycle progression in breast cancer cells. Endocr Relat Cancer. 2003;10:179-86.

61. Foster JS, Henley DC, Ahamed S, Wimalasena J. Estrogens and cell cycle regulation in breast cancer. Trends Endocrinol Metab. 2001;12:320-7.

62. Thangavel C, Dean JL, Ertel A, Knudsen KE, Aldaz CM, Witkiewicz AK, Clarke $R$, Knudsen ES. Therapeutically activating RB: reestablishing cell cycle control in endocrine therapy-resistant breast cancer. Endocr Relat Cancer. 2011; 18(3):333-45.

63. Xi J, Oza A, Thomas S, Ademuyiwa F, Weilbaecher K, Suresh R, Bose R, Cherian M, Hernandez-Aya L, Frith A, Peterson L, Luo J, Krishnamurthy J, Ma CX. Retrospective analysis of treatment patterns and effectiveness of palbociclib and subsequent regimens in metastatic breast cancer. J Natl Compr Cancer Netw. 2019;17:141-7.

64. O'Leary B, Hrebien S, Morden JP, Beaney M, Fribbens C, Huang X, Liu Y, Bartlett CH, Koehler M, Crisofanilli M, Garcia-Murillas I, Bliss JM, Turner NC. Early circulating tumor DNA dynamics and clonal selection with palbociclib and fulvestrant for breast cancer. Nat Commun. 2018:9:896. https://doi.org/ 10.1038/s41467-018-03215-X.

65. Gyanchandani R, Kota KJ, Jonnalagadda AR, Minteer T, Knapick BA, Oesterreich S, Brufsky AM, Lee AV, Puhalla SL. Detection of ESR1 mutations in circulating cell-free DNA from patients with metastatic breast cancer treated with palbociclib and letrozole. Oncotarget. 2016;8:66901-11.
66. Harrod A, Fulton J, Nguyen VTM, Periyasamy M, Ramos-Garcia L, Lai CF, Metodieva G, de Giorgio A, Williams RL, Santos DB, Gomez PJ, Lin ML, Metodiev MV, Stebbing J, Castellano L, Magnani L, Coombes RC, Buluwela L, Ali S. Genomic modeling of the ESR1 Y537S mutation for evaluating function and new therapeutic approaches for metastatic breast cancer. Oncogene. 2017;36:2286-96.

67. Toy W, Weir H, Razavi P, Lawson M, Goeppert AU, Mazzola AM, Smith A, Wilson J, Morrow C, Wong WL, De Stanchina E, Carlson KE, Martin TS, Uddin S, Li Z, Fanning S, Katzenellenbogen JA, Greene G, Baselga J, Chandarlapaty S. Activating ESR1 mutations differentially affects the efficacy of ER antagonists. Cancer Discov. 2017;7:277-87.

68. Mukohara T. PI3K mutations in breast cancer: prognostic and therapeutic implications. Breast Cancer (Dove Med Press). 2015; 7:111-123.

69. Cancer Genome Atlas Network. Comprehensive molecular portraits of human breast tumours. Nature. 2012;490:61-70.

70. Juric D, Ciruelos E, Rubovszky G, Campone M, Loibl S, Rugo HS, Iwata H, Conte P, Mayer IA, Kaufman B, Yamashita T, Lu Y-S, Inoue K, Takahashi M, Pápai Z, Longin A-S, Mills D, Wilke C, Sellami D, and Andre F. Alpelisib + fulvestrant for advanced breast cancer: subgroup analyses from the phase III SOLAR-1 trial. Cancer Res February 152019 (79) (4 Supplement) GS3-08; DOI: https://doi.org/10.1158/1538-7445.SABCS18-GS3-08.

\section{Publisher's Note}

Springer Nature remains neutral with regard to jurisdictional claims in published maps and institutional affiliations.
Ready to submit your research? Choose BMC and benefit from:

- fast, convenient online submission

- thorough peer review by experienced researchers in your field

- rapid publication on acceptance

- support for research data, including large and complex data types

- gold Open Access which fosters wider collaboration and increased citations

- maximum visibility for your research: over $100 \mathrm{M}$ website views per year

At BMC, research is always in progress.

Learn more biomedcentral.com/submissions 